\title{
El proceso de amores de Calisto y Melibea frente a la tradición
}

\author{
Kevin Matos \\ Universidad de Puerto Rico
}

\section{RESUMEN}

La historia de los dos amantes Calisto y Melibea sigue en muchos aspectos los códigos amatorios repetidos una y otra vez en la literatura medieval, aunque, por momentos, tales códigos no se adecúan del todo a la realidad de los enamorados. Para aquilatar sus singularidades, este trabajo explora al detalle el proceso de amores que siguen los protagonistas, desde su primer encuentro hasta llegar al tálamo venéreo, siempre teniendo en cuenta la tradición o el contexto en el que se enmarcan. Será en el tálamo venéreo donde el lector halle el culmen de la rebeldía erótica de Melibea, quien rechaza una tradición de siglos y propone a viva voz nada menos que nuevos modos de hacer el amor.

PALABRAS CLAVE: amor, erotismo, Celestina, ars amandi, sexo.

\section{Calisto and Melibea's love process compared to tradition}

\section{ABSTRACT}

The story of the two lovers Calisto and Melibea follows, in many facets, the amatory codes made repeatedly in medieval literature, although, at times, such codes do not match wholly with the reality of the lovers. To assess their singularities, this work explores the love procedures that the protagonists follow, while keeping in mind the tradition or context where they reside. It is in the lovers' bed where the reader will find the summit of the erotic defiance of Melibea, who rejects a tradition of centuries and proposes nothing less than new ways to make love.

KEYWORDS: love, eroticism, Celestina, ars amandi, sex.

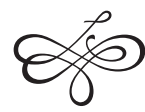


No faltan en las letras medievales los manuales dedicados a la pormenorización del proceso de amores, es decir, de los códigos que han de seguir los enamorados para la realización adecuada y finalmente fructífera de sus amores. El amor tiene su arte y sus leyes. Existe todo un complicado protocolo - bastante rígido, por cierto- que estipula desde cómo un varón ha de acercarse a su dama y cómo esta debe responderle hasta cómo han de yacer juntos en la cama. Los autores antiguos, desde los comentaristas de Horacio y Terencio, hasta los desenfadados goliardos del Medioevo, resumen el proceso abreviadamente: «Visus et alloquium, contactus et oscula, factum ${ }^{1}$. Ver, hablar, tocar, besar, hacer. Pero cada una de estas fases tiene que ser vivida de un modo particular, siempre acorde con el decoro propio de la época. Andreas Capellanus, que reduce los grados a cuatro ${ }^{2}$, advierte algo muy importante: no se ha de acelerar el proceso ni llegar demasiado pronto al último grado, sino que la consecución debe ser gradual, pues «carius habetur quod pluribus est laboribus acquisitum quam quod sollicitudine modica possidetur» ${ }^{3}(1985$, p. 88). El autor precisa el adecuado proceder de la mujer:

Sapientes tamen feminas non decet tam repentina quemquam concessione ditare, ut prioribus praetermissis gradibus ad quarti statim gradus prosiliant largitionem, sed ordine solent procedere tali. Debet enim primo spei uti largitione mulier, et si cognoverit amantem spei largitione accepta in bonis moribus augmentari, ad gradum mulier non vereatur devenire secundum. Et sic gradatim usque ad quartum deveniat gradum, si ipsum hac re invenerit per omnia dignum ${ }^{4}$. (1985, p. 88)

Visto desde la lejanía temporal, la ceremonia de los amadores medievales parece calculada paso a paso como un delicado minué cortesano. En

1.- Así la exposición de Alain de Lille. Donato los presenta del siguiente modo en su comentario al Eunuco de Terencio: «CERTE EXTREMA LINEA et hoc recte, quia quinque lineae perfectae sunt ad amorem: prima uisus, secunda alloquii, tertia tactus, quarta osculi, quinta coitus» (apud Friedman 1965, p. 172). Para el desarrollo y codificación de los gradus amoris tanto en la literatura como en textos doctrinales, véase Lionel J. Friedman (1965) y también Curtius (1955, pp. 716-718) y Dronke (1968, pp. 488-489).

2.- «Primus in spei datione consistit, secundus in osculi exhibitione, tertius in amplexus fruitione, quartus in totius personae concessione finitur» (1985, p. 86).

3.- «Se aprecia más lo que se adquiere tras muchos esfuerzos que lo que se llega a poseer sin apenas preocuparse» (1985, p. 89).

4.- "No conviene a las mujeres prudentes colmar a nadie con tan pronta entrega; es decir, que, pasando por alto los primeros grados, se lancen a la pródiga entrega del cuarto grado, sino que se acostumbra a proceder con el siguiente orden: primero la mujer debe dar esperanzas $y$, si se da cuenta de que el amante, tras aceptar la esperanza, adquiere mejores costumbres, entonces no tiene por qué temer pasar al segundo grado. Y así gradualmente hasta llegar al cuarto grado, si es que lo encuentra digno en todos los aspectos de tal cosa» (1985, pp. 87-89). 
las páginas que siguen, nos ocuparemos de acompañar a Calisto y Melibea en su proceso de amores, siempre teniendo en cuenta el contexto al que pertenecen y la tradición consagrada que emulan en todos y cada uno de sus encuentros. Esta tradición amatoria occidental nos ayudará a entender la obra en sus propios términos y aquilatar su originalidad a partir de la tradición en la que se enmarca. Adelantamos, eso sí, que los amantes no siempre serán fieles a las convenciones, por lo que subrayaremos las incongruencias entre lo esperado y la realidad de los enamorados. ${ }^{5}$

\section{Primer encuentro de los amantes}

Todos los pasos que han de dar los buenos amadores conducen a una misma meta: alcanzar la plenitud erótica. Pero no siempre los amadores alcanzarán a vivir la gloria que esta entraña. Hasta no ver cumplida tal bienaventuranza, serán penados, siempre al borde de la muerte que los espera si no logran satisfacer el deseo que los ha sumido en un mal que urgentemente pide remedio, pues desemboca en el conocido amor hereos, acerca de cuyo peligro y destrucción tan largamente hubieron de teorizar los médicos de la época. "La pronosticación es tal que si los hereos no son curados, caen en manía o se mueren", dictaminaba un médico en el siglo XIV, Bernardo de Gordonio en su Lilio de medicina (1991, p. 108). Tal peligro constriñe al afligido a solicitar remedio a su dama, un remedio que consiste nada menos que en la entrega corpórea total de ella. El enamorado reclama que se trata de un asunto de vida o muerte. Este mal de amores y la urgencia de salvar la propia vida - ya en bromas o ya en veras- se convirtió, pues, en un paso esencial del proceso de galanteo que habrían de seguir muchos penados para salvar sus vidas. Lo recomendaba desde antiguo el principal magister amoris de Occidente, Ovidio ${ }^{6}$, y lo repitieron sin cesar sus continuadores, amparados a su vez en el saber médico que teorizaba sobre la destructiva pasión amorosa. A decir verdad, no todos los amadores medievales se conformaron con regodearse en su dolor, su dolorosa goia o su dolce tormento. Ese amor que ennoblecía los corazones de poetas como Guido Guinizelli, y que destruía poco a poco a poetas

5.- Es preciso decir que Emilio de Miguel Marínez (2000) ha examinado de modo admirable cómo Melibea vive el amor, haciendo hincapié en su "verosimilitud humana». El autor acompaña a la protagonista en su proceso de amores, aunque sin aludir al contexto o a la tradición que reverbera en cada una de sus palabras y actos. También Eukene Lacarra Lanz (2000) ha estudiado el erotismo en la relación de Calisto y Melibea, centrándose en los cuatro encuentros de los enamorados. En el presente estudio intentaremos ir más allá de sus estudios pioneros y poner en contexto el protocolo amatorio dentro de su tradición.

6.- Por poner un ejemplo: «Est tibi agendus amans, imitandaque vulnera verbis; / Haec tibi quaeratur qualibet arte fides" (Ars amatoria, libro I, vv. 611-612). Y en el Ovidio traducido por fray Melchor de la Serna en el siglo xvi: «Si quieres el remedio de tu llama, / procura a compasión mover tu dama» (2016, p. 78; vv. 903-904). 
como Guido Cavalcanti, no siempre fue vivido de la misma manera. Un gran grupo de amadores del Cancionero español, por ejemplo, advirtieron constantemente a sus damas la gran culpa que recaería sobre ellas si los dejaban morir sin haberles dado remedio, es decir, sin haberse entregado a ellos. «Recebir deves pesar / por matar y ver morir / tal servidor», advierte Lope de Estúñiga (I, 81, vv. 76-78) ${ }^{7}$. «Por bienquerer, se malquiso: / por agena culpa muere», se pregona sobre don Diego López de Haro (IV, 20*, vv. 31-33). Juan de Mena le propone sin ambages a su dama que opte por un pecado menor - a saber, la fornicación - al gravísimo pecado de matar: "pecad por no pecar / tan grave como matar / a mí, que no tengo culpa» (I, 65, vv. 78-80). Pues no ha sido otra cosa que la vista de una forma bella considerada "plazentera", es decir, de una dama hermosa, la causa de toda una cadena de efectos psicológicos y fisiológicos — como la tristeza extrema, la palidez o tez amarillenta, la falta de apetito, el insomnio, etcétera- que suponen el riesgo de desembocar en melancolía, en locura o simplemente en la muerte 8 . He dicho en bromas o en veras, pues algunos médicos, como Francisco López de Villalobos, contemporáneo de Rojas, supieron que esta "enfermedad de los cortessanos» era un verdadero «hito de los trouadores» que las más de las veces no era genuina, sino fingida. De ahí que siempre figure en las instrucciones a los galanes este esencial ingrediente de seducción: apelar a la compasión de la dama y suscitar su culpabilidad por la presunta «muerte» de su enamorado. Este es, digamos, el punto de arranque del galanteo luego de la mirada inicial y se considera la mejor manera de iniciar el acercamiento a la dama, que queda, pues, plenamente justificado. O ser amado o perecer?.

Es por eso que en la Tragicomedia, Calisto inicia su primer acercamiento a Melibea - que suponemos a escondidas, a juzgar por el arriesgado contenido de la conversación - celebrando la grandeza de Dios, que ha concedido el poder a Natura — vicaria o ministra suya-, no solo de dotar a Melibea de tan perfecta hermosura, sino de permitirle a él, «inmérito», verla y manifestarle su «secreto dolor». Pues es precisamente la necesidad

7.- Para la poesía del Cancionero general, reunida por Hernando del Castillo, me sirvo de la edición en cinco tomos de Joaquín González Cuenca (Castillo 2004). Indico entre paréntesis en números romanos el tomo, seguido del número del poema y finalmente los versos.

8.- El proceso psicofisiológico aquí sugerido es muy complejo y no tenemos el espacio para deternernos a explicarlo. Baste con decir que el individuo retiene la forma impresa del objeto del deseo en la fantasía y la recrea continuamente hasta que deviene una idea obsesiva que acaba por ofuscar «el juizio e la razón» (Gordonio 1991, p. 107), de modo que el sujeto se ve constreñido a anteponer a cualquier cosa la satisfacción de sus aspiraciones eróticas. En otras palabras, el llamado amor hereos consiste en un intenso deseo sexual y en una aflicción de los pensamientos que acaba por trastornar el juicio. Remito al lector a los magníficos trabajos, de consulta obligada, de Ciavolella (1976), Lowes (1914), Nardi (1959), Beecher y Ciavolella (1990) y Wack (1990). Para el caso específico de la Tragicomedia, véanse principalmente Amasuno (2005), Lacarra (2007) y Morros (2009 y 2010).

9.- Desarrollo ampliamente todas estas ideas en Matos (2018b). 
de confesar ese «secreto dolor", causado por la vista de la dama, lo que constriñe a Calisto a dirigirse por vez primera a Melibea. El enamorado hace gala de un lenguaje de altos quilates que se adecúa perfectamente, pese a su excesiva verborrea, a los códigos esperados ${ }^{10}$. Y esto debido debido al interés que parece mostrar la doncella. Su "¿En qué, Calisto?», que sin duda encubre un "dime más», le da permiso al penado para confesar su pasión ${ }^{11}$. La joven, conocedora del «secreto dolor» que atenaza a su adorador, se arriesga aún más y promete: «Pues aun más igual galardón te daré yo, si perseveras» (I, p. 27) ${ }^{12}$. A ningún lector u oyente podría escapársele la carga erótica de la palabra "galardón", tan ambigua en el código amatorio cortesano, basado, por cierto, en la perseverancia $y$ en la persistencia ${ }^{13}$. Calisto vislumbra el sumo bien y celebra jubiloso su bienaventuranza: "Oh bienaventuradas orejas mías que indignamente tan gran palabra habéis oído» (I, p. 28). Pero, de súbito, Melibea denuncia airada el "loco atrevimiento» y la «torpe» intención, es decir, deshonesta, impúdica o lujuriosa, de Calisto, quien atenta contra su honra. Era de esperarse. Pero la joven, al rechazar la elevada exclamación del enamorado, menciona incluso la palabra «deleite». ¿Ha sido imprudente la respuesta de Calisto? ¿Sugiere acaso el «deleite» deshonesto que tanto parece escandalizar a la joven? Lo cierto es que no. Más allá de los equívocos tan propios del discurso cortesano ${ }^{14}$, quien ha mencionado la palabra «delei-

10.- Es frecuente despachar a Calisto como una mera "parodia del amante cortés» (Deyermond 1961, Martin McCash 2001, Severin 1984, Lacarra 1989, entre otros), lo cual no es incierto, pero se olvida que el joven enamorado no hace nada distinto a lo que hicieran muchos de sus predecesores y que aconsejara el propio Andreas Capellanus en su tratado De amore: el lenguaje idealizante, más allá de reverencias y ternuras, es, al decir de Peter Dronke, «a blatantly part of a seducer's strategy to get a woman into bed» (1994, p. 59). En lo mismo tercia Paolo Cherchi al describir los diálogos que figuran en el De amore: «A futile exercise indeed: the lovers try to extenuate their passio with eloquent appeals to their probitas, but they never succeed in persuading their ladies to love them in return. The ladies point out, often hilariously, that behind all the apparatus of courtliness and the presumption of moral beauty on the part of their interlocutors, there is only a desire to coire» (1994, pp. 37-38).

11.- Lo vio muy bien Lope de Vega en Las fortunas de Diana: «Aquí me acuerdo, señora Leonarda, de aquellas primeras palabras de la tragedia famosa de Celestina, cuando Calisto le dijo: «En esto veo, Melibea, la grandeza de Dios». Y ella respondió: «¿En qué, Calisto?». Porque decía un gran cortesano que si Melibea no respondiera entonces "¿en qué, Calisto?» que ni había libro de Celestina, ni los amores de los dos pasaran adelante» (2017, pp. 111-112).

12.- Cito siempre por la edición de Lobera et alii (2011). Para facilidad del lector, indico el auto en números romanos y luego la página.

13.- Russell, en su edición, menciona tres posibles sentidos y se decanta por que Melibea lo emplea en el ambiguo de 'recompensa (premio o castigo)', mientras que Calisto lo entiende como 'rendición sexual', lo cual provoca la respuesta airada de ella. Para mí, sin embargo, Melibea es consciente de la carga sexual de su promesa, como aclaro a continuación.

14.- Sobre la ambigüedad léxica que caracteriza la literatura amatoria de la época, véase especialmente Keith Whinnom (1981). 
te» y todo lo que ello implica ha sido Melibea ${ }^{15}$, por lo que no es difícil sospechar que se trata más bien de un "sí, pero no" ${ }^{16}$, de una estrategia para salvaguardar las apariencias y al mismo tiempo avivar el deseo del requeridor ${ }^{17}$. Melibea bien pudo haber cortado en seco la conversación con el «torpe» y locuaz Calisto.

¿Qué hubiera hecho otra en su lugar? Pensemos, por ejemplo, en el Arcipreste de Hita o don Melón y en doña Endrina. Aconsejado por don Amor y por doña Venus, el enamorado, al ver a la dama que lo trae penado al contonearse por la plaza, decide confesarle su "quexura del amor» (v. 659d). Sabe que "tal lugar non era para fablar en amores» (v. 654a), por lo que disimula conocerla de toda la vida y finge una conversación trivial, pero en cuanto se hace oportuno le susurra al oído sus verdaderas intenciones: «ámovos más que a Dios» (v. 661c).

Con la grant pena que paso vengo a vos dezir mi quexa: vuestro amor e deseo, que me afinca e me aquexa, no.s me tira, no.s me parte, non me suelta, non me dexa; tanto [más] me da la muerte quanto más se me alexa.

(estrofa 662)

El penado confiesa apasionadamente su pena. Ella, sin embargo, permanece "sorda» a sus instancias — según le recrimina él一, hasta que se ve obligada a contestar: "Vuestros dichos non los preçio dos piñones» (v. 664d). De entrada, la dama corta la conversación, lo que no parece hacer Melibea hasta mucho después. Sabe lo que se esconde detrás de los suspiros y los corteses lamentos, es decir, lo que significa tal «quexura de amor». Aunque también es cierto que su encubierto deseo la convence enseguida de alejarse del ojo público, entrar a un portal y sentarse a es-

15.- Lo supo ver Salvador de Madariaga: «Ya sabemos, desde la primera escena, que es su primer encuentro con Calisto, que Melibea tiene la imaginación bien bañada en lo carnal» (1972, p. 79).

16.- Eukene Lacarra Lanz está de acuerdo en que Melibea muestra conocer muy bien el léxico erótico y los equívocos que los términos empleados por Calisto entrañan («secreto dolor», «merced», "galardón», «alcanzar», «bienaventuranza»...) y piensa que la ira de Melibea se debe a "las amenazas a su integridad física» (2000, pp. 129-130). En efecto, es la respuesta esperada a fin de salvaguardar la honra —o, más bien, las apariencias- . Al igual que Lacarra, pienso que Melibea disimula su pasión. Lo hace porque sabe que es lo que tiene que hacer, de momento. Coincido con Emilio de Miguel Martínez cuando escribe: «¿A qué ha jugado Melibea con este paso desde el halagado consentimiento a la más cruda reprobación? Probablemente a lo único que podía jugar. Al sí, pero no. O al no, pero sí» (2000, p. 37). Por tanto, no puedo estar de acuerdo con quienes piensan que la «furia de Melibea» significa un rechazo implacable a Calisto por no considerarlo un fino amador al no servirla como debería según el "código cortés», tal como sugieren Green (1953), Deyermond (1961), Martin MacCash (2001) y Corfis (1996). Es preciso recordar que, a partir de Dronke (1994), no se tiende a ver más el texto de Andreas Capellanus como un manual de amor cortés.

17.- Lo cual es cónsono con uno de los consejos ovidianos: «Fac timeat speretque simul» (Ars amatoria, libro III, v. 477). 
cuchar las quejas de su pretendiente. Poco, sin embargo, logra conseguir el penado en tal alloquium, pues el proceso de amores ha de llevarse con paciencia y perseverancia paso a paso. No es poco, con todo, lo que logra en penado: cautivar el interés de la dama, despertar su deseo. El enamorado, además, se asegura de tener esperanzas de alcanzar su galardón y así puede pensar en pasar al próximo paso. Ya conocemos las instrucciones de Andreas Capellanus. "Carius habetur quod pluribus est laboribus acquisitum quam quod sollicitudine modica possidetur ${ }^{18}$.

Celestina habrá de descodificarle a Calisto este tipo de respuestas. Son imprescindibles, explicará,

los golpes, los desvíos, los menosprecios, desdenes que muestran aquéllas en los principios de sus requerimientos de amor, para que sea después en más tenida su dádiva[.] Que a quien más quieren, peor hablan; y si así no fuese, ninguna diferencia habría entre las públicas que aman, a las escondidas doncellas, si todas dijesen "sí» a la entrada de su primer requerimiento, en viendo que de alguno eran amadas. Las cuales, aunque están abrasadas y encendidas de vivos fuegos de amor, por su honestidad muestran un frío esterior, un sosegado vulto, un aplacible desvío, un constante ánimo y casto propósito, unas palabras agras que la propia lengua se maravilla del gran sofrimiento suyo, que la hacen forzosamente confesar el contrario de lo que sienten. (VI, pp. 146-147)

Por eso Melibea denuncia airada el «loco atrevimiento» de Calisto al vislumbrar el «deleite» que lo aguarda si persevera en su servicio, un «deleite» que ha verbalizado ella y no su requeridor, acaso para afirmar su "casto propósito». Lo declarará sin aspavientos Sempronio a su amo cuando lo vea penado: «Por rigores comienzan el ofrecimiento que de sí quieren hacer» (I, p. 41) $)^{19}$. También doña Venus alerta al Arcipreste sobre las «malas respuestas» de las damas (v. 613a). La ira, sincera o no, es parte integral de la preceptiva erótica que siguen los amantes del Medioevo, basada en

18.- Parece tenerlo en cuenta doña Endrina cuando amonesta a la alcahueta por la apremiante instancia: «non me afinques tanto luego el primero día» (v. 764d).

19.- Lo dijo Ovidio: «Utque viro furtiva venus, sic grata puellae: / Vir male dissimulat: tectius illa cupit» (Ars amatoria, libro I, vv. 275-276), es decir: «El amor furtivo es tan agradable para una mujer como para un varón: el varón no sabe disimularlo, pero ella lo desea más escondidamente» (1995, p. 363). De ahí que el servicio amoroso se base en la persistencia: «Ergo age, ne dubita cunctas sperare puellas; / Vix erit e multis quae neget una tibi. / Quae dant quaeque negant, gaudent tamen esse rogatae» (vv. 343-345): "Así que, ea, no dudes en tener esperanzas acerca de todas las mujeres: apenas habrá una, entre las muchas que hay, que te dé una negativa. Tanto las que acceden como las que se niegan, se alegran no obstante de que se las corteje» (1995, p. 367). Lo mismo asegura doña Venus: «apena que de mill una te lo niege, mas desdeña: / aunque la muger calle, en ello piensa e sueña» (vv. 610c y d). 
el disimulo. A la dama le es siempre preciso guardar las apariencias y cuidarse de las habladurías. Sin esa "mala respuesta» inicial, no habría proceso de amores: "ni Calisto viviera quejoso", ni habría servicio, ni habría mayor interés en seguir adelante.

Calisto y Melibea inician sus amores con un brevísimo pero extraordinario tête à tête, lo cual no se da siempre desde tan temprano en este género de obras. Es más habitual que el primer intercambio verbal se produzca a través de la intervención de un medianero que casi siempre porta un mensaje o alguna misiva de parte del requeridor. Ello sucederá también, en su momento, en la Tragicomedia. Pero ya de entrada, en esta primera escena, hemos constatado dos ingredientes esenciales en todo proceso de amores: el penado enamorado, que sufre de un «secreto dolor» que lo destruye y que urgentemente pide remedio, y la dama esquiva y airada que rechaza implacablemente al penado por defender su honra a fin de guardar las apariencias. Todo ello aparece en la Tragicomedia aureolado de equívocos y, por supuesto, de gran humor. Desde el inicio, sin embargo, Melibea comienza a delatar una autonomía intrigante, aun desde el ballet cronometrado de su conducta obligada.

Antes de proseguir, es oportuno que revisemos uno de los tantos artes amandi que recogen parte de la preceptiva que siguen la gran mayoría de los amantes literarios del Medioevo, entre ellos, Calisto y Melibea. Estamos ante el telón de fondo teórico frente al cual discurren los amores de los enamorados y conviene familiarizarnos con él a fin de comprender la obra en sus propios términos.

\section{Un curioso compendio de preceptos eróticos}

Son archiconocidas las lecciones de Ovidio en su Ars amatoria y sus refundiciones medievales, como el De amore de Andreas Capellanus o el manual de cortesía Facetus, moribus et vita, y las puestas en práctica de sus preceptos en la comedia elegíaca latina, la comedia humanística, los cantos goliardescos y otros textos afines tanto en latín como en romance, como el propio libro del Arcipreste. Todos guardan algo en común: están dirigidos principalmente al varón y se ocupan de pormenorizar el prodecer del galán para lograr seducir a su doncella. Pero una sorpresa aguarda al lector en un librillo italiano que, aunque un poco posterior a la Tragicomedia (vio la luz en 1547), recoge todas las prácticas repetidas en la literatura medieval hispánica. Me refiero al Specchio d'amore de Bartolomeo Gottifredi. Las lecciones que allí figuran son cónsonas con todas las preceptivas eróticas que conforman la tradición erotológica seguida por los amantes medievales. Pero la gran novedad es que el texto constituye un manual dirigido a un público femenino, al menos estructuralmente. 
Una joven de quince años, Maddalena, es aleccionada por su ama de llaves, Coppina, en el arte de enamorarse. La vieja capta de inmediato la atención de la joven al describir el amor como "cosa ottima e santa" (1912, p. 254), pero se cuida de hablar sottovoce para que nadie descubra el que será su nuevo secreto compartido. Le enseña la materia básica: qué es el amor, de quién se debe enamorar, cuáles son las señales de que el hombre está interesado, cómo ella debe corresponder a tales señales, cuáles son los síntomas del amor, entre otras cosas. Y, luego, la astuta marisabidilla del amor procede a enumerar los pasos que ha de seguir la joven para estar a la altura «di queste galanterie» (1912, p. 270). Pero antes le deja muy claro: «Ed è ben fatto non darsi cosí alla prima in preda degli amanti», pues "cosa lungamente piatita e difficilmente ottenuta piú cara si suol tenere» (1912, p. 257). Ha de cuidarse de las prisas en el proceso y es preciso avanzar gradualmente, tal como proponía Andreas Capellanus. Y ha de velar siempre por salvaguardar su honra ante la sociedad. A la dama le es siempre preciso guardar las apariencias, por lo que debe hacerse una experta en el arte del disimulo.

"Amore è un fuoco invisibile» (1912, p. 258), explica Coppina, un fuego que arde escondido en el fondo del corazón y que se nutre de la esperanza de obtener el placer que este entraña. Una vez encendido en ella ese "desio di piacere» (1912, p. 263), "desiderio di goder la cosa amata» (1912, p. 291), debe dar alguna señal al hombre — acaso velada - de que tiene esperanzas de alcanzar su galardón. Entonces, él procederá a enviar una mensajera o alcahueta que "fará tentare» $(1912$, p. 268) a la requerida en amores. La vieja se mostrará benigna y pía, y le suplicará: «Gentil madonna, abbia compassione d'un cuore che per voi miseramente langue». Ha dejado a un enfermo de muerte que con una palabra sola bastará para sanarse. Le pondrá en mano una carta de parte del penado amante, pero la joven ha de ser muy cauta, pues cualquier paso en falso podría arruinarlo todo. Estas son las instrucciones precisas de Coppina: "A questo io voglio che tu ti mostri turbata e da te minacciosamente la scacci, fingendo non voler né veder né udir alcuna sua cosa. Potresti anche pigliar la lettera ed in sua presenza stracciarla e gettarla per la camera in pezzi, e, tosto, ch'ella fusse partita, raccoglierla e, tornatala insieme, leggerla, dandogli per qualche tua fidata risposta» $(1912$, p. 268). La mensajera y su favorecido sabrán interpretar muy bien cuál es la respuesta. Él persistirá en su servicio. Insistirá en el peligro de muerte en que se halla si no es remediado a tiempo, aunque asegura que prefiere morir antes que poner sus ojos en otra. Ella se asegurará así de su firmeza y fidelidad.

Tras una comprimida lista de consejos prácticos ${ }^{20}$, toca preparar a Maddalena para su primer encuentro formal con su pretendiente Fortu-

20.- Entre estos, Coppina insta a Maddalena a estudiarse la poesía de Petrarca y de Boccaccio para saber cómo interpretar y cómo responder los mensajes de su requeridor. Le sugiere 
nato. La joven confiesa sus temores, pero ha de saber renunciar a ellos, pues «non conosce paura un cuore innamorato» (1912, p. 281). Deben concertar su encuentro en un lugar donde les sea lícito abrazarse. Pero enseguida comienzan las advertencias de la maestra: "Io non voglio che tu glielo neghi, ma che sopra la difficultá ti scusi, usando sempre dolci e cortesi parole». Él no se detendrá. Sus impúdicas manos no querrán estar quedas y osarán acercarse a partes más secretas. «Non ti lascia toccare cosí alla prima», ataja Coppina. La joven debe empezar a mostrarse algo turbada y hacer cuanto le sea posible por desasirse de esas deshonestas manos, haciéndole prometer que dejará ya su «enojoso uso» ("[di] dare noia»). Él lo prometerá, sí, pero ¿cómo es posible que un sediento en medio del agua se resista a beber? (1912, pp. 281-282). Los movimientos empiezan a ser cada vez más raudos. Cumple avanzar al próximo gradus amoris. Maddalena pregunta: «Volete ch'io mi lasci basciare?» (1912, p. 283), a lo que responde Coppina: «Farai vista di non volere: pur finalmente lásciati sforzare». Ella debe resistirse, aunque sin poner demasiado empeño en ello, y, finalmente, se ha de dejar forzar. Ante sus remilgos, él argumentará que "le occasioni perdute non possono adietro ritornare». La joven, desconcertada ante la rápida concatenación de procedimientos, no logra contener la ansiedad y pregunta: «Lo lascierò dunque far di me ciò ch'egli vorrá?». La respuesta de Coppina no puede ser más clara ni contundente: «il vedere, il favellare, il toccare e tutti gli altri trattenimenti amorosi sono pene, miserie e passioni, senza la speranza di quel dolce fine». Y, así, enseguida se consuma la plena realización del proceso amoroso.

Henos, pues, ante un verdadero arte de amar, aunque no ya dirigido al varón, sino a una doncella. Salta a la vista, con todo, que las doctrinas amatorias expuestas no difieren demasiado de aquellas que se enseñan en manuales de cortesía galante como el Facetus, moribus et vita y otras exposiciones inspiradas en las lecciones ovidianas. Las instrucciones de Coppina, aunque consideran algunas estrategias para «seducir» al hombre, no son otra cosa que un compendio de las respuestas esperadas por parte de la fémina al proceder del varón, siempre teniendo en cuenta el protocolo necesario para guardar las apariencias y no parecer una mujer ligera, al tiempo que aviva la llama de amor del enamorado.

Cumple, pues, que examinemos al detalle la puesta en práctica de algunos de estos consejos y sigamos acompañando a Calisto y a Melibea en su proceso de amores. sapere» (1912, p. 273). 


\section{Tras el primer encuentro de los amantes}

Antes de que Celestina le descodifique la respuesta airada de Melibea a Calisto, el joven enamorado corre desesperado a encerrarse en su cuarto en la más absoluta oscuridad y, ensimismado en su pena, decide invocar la muerte. No ha logrado captar el sentido que entraña el lenguaje equívoco de Melibea y ve tambalearse las esperanzas de alcanzar el galardón prometido: no cabe duda de que la opacidad mental de Calisto constituye parte de la parodia de los autores. La agudeza mental de su amada lo supera por mucho. El criado Sempronio advierte enseguida el mal que aqueja a su amo, esa común "enfermedad de los cortessanos».

Calisto sufre obcecado en su pasión, pues la muerte que amenaza al enfermo que no es remediado a tiempo por su dama no solo fue una estrategia retórica de seducción, sino que alcanzó a algunos firmes amadores que vivían cautivos en la cárcel del amor. Este trágico fin alcanzó a Leriano, en la Cárcel de amor de Diego de San Pedro. El «auctor», personaje de su propia obra, ejerce de medianero para intentar conseguir el favor de Laureola para que evite la muerte que ella misma causa. Ella, aunque piadosa, sabe en qué consiste el remedio solicitado y se ve imposibilitada a ello: «Si pudiese remediar su mal sin amanzillar mi onra, no con menos afición que tú lo pides yo lo haría; mas ya tú conosces cuánto las mugeres deven ser más obligadas a su fama que a su vida (...) Pues si el bevir de Leriano a de ser con la muerte désta, tú juzga a quién con más razón devo ser piadosa, a mí o a su mal» (2015, pp. 83-84). La doncella permanece firme en su decisión, por lo que, al final, a Leriano no le queda otra opción que morir ${ }^{21}$.

Es preciso insistir que esa enfermedad que tanto aqueja a los cortesanos, incluido Calisto, y a los poetas no es sino un deseo ferviente y desmedido de alcanzar carnalmente a la dama hermosa que los ha penado, tal como declara el médico Gerardo de Solo: «amorereos est amor multum fortis feruens et assiduus circa mulierem propter actus coitus exercendos» (apud Lowes 1914, p. 510). De manera que el remedio más efectivo recomendado por los médicos para salvar al enfermo de amor que corre riesgo de muerte, ya lo he anticipado, es el coito, preferiblemente con la causadora del mal. Lo explicita muy a las claras el médico portugués Velasco de Taranta: «Prima est que detur sibi illa quam diligit» (f. 23r). Por eso Sempronio, que no se complica con la ceremoniosa retórica y el protocolo de los cortesanos, tras identificar el mal de su amo, procede a proponer el remedio: "traérgela he hasta la cama» (I, p. 47). Y para ello se precisa de la intervención de una astuta y sagaz medianera, figura consagrada también por la tradición. No la hay mejor que Celestina. 


\section{En busca de remedio: el primer encuentro entre Melibea y Celestina}

Una vez el pretendiente afiance las esperanzas de alcanzar a la dama que desea, el próximo paso es enviarle una mensajera. Advertía Coppina que la alcahueta la "fará tentare» con súplicas como esta: "Gentil madonna, abbia compassione d'un cuore che per voi miseramente langue». Ya sabemos el peligro de muerte en que se encuentra el enamorado no correspondido a tiempo. Así se lo deja saber Celestina a Melibea, entreverando su petición con fórmulas eclesiásticas para acentuar su condición benigna y pía: «Yo dejo un enfermo a la muerte, que con sola una palabra de tu noble boca salida que le lleve metida en mi seno, tiene por fe que sanará» (IV, p. 124). Conocemos de sobra cuál es la palabra sanadora, esa que nunca pudo pronunciar Laureola. Entre muestras de enojo y de compasión, Melibea quiere saber más, pero sabe que llegado este momento debe estallar en ira:
Desvergonzada barbuda, ¿qué siente ese perdido que con tanta pasión vienes? De locura será su mal. ¿Qué te pare- ce? (...) Quemada seas, alcahueta, falsa, hechicera, ene- miga de honestidad, causadora de secretos yerros. ¡Jesú, Jesú! ¡Quítamela, Lucrecia, de delante, que me fino, que no me ha dejado gota de sangre en el cuerpo! Bien se lo merece esto y más, quien a estas tales da oídos. Por cierto, si no mirase a mi honestidad y por no publicar su osadía dese atrevido, yo te hiciera, malvada, que tu razón y vida acabaran en un tiempo. (IV, pp. 126-127)

La joven, que sobrado sabe ante quién está parada, a juzgar por las descripciones ofrecidas de Celestina, sabe que debe reaccionar airada y hasta recurre a una temeraria amenaza. Era lo esperado. También esta «mala respuesta» figura, obviamente, en los manuales. Coppina ordenaba hacer trizas de modo furibundo cualquier carta recibida a través de una alcahueta y que echara a la alcahueta con amenazas. Laureola, «larga en enojo», amenaza de muerte al atrevido "auctor», que media por Leriano: «Si, como eres de España, fueras de Macedonia, tu razonamiento y tu vida acabaran a un tiempo» (2015, p. 77). Y como sabe que la respuesta airada forma parte del disimulo aconsejado por la preceptiva erótica tradicional, se ve obligada a aclarar más tarde que no ha sido así, pues el medianero interpretó su alteración como señal de interés, como era de esperar ${ }^{22}$. Lo mismo sucede en la Historia de duobus amantibus, de Eneas Silvio Piccolomini, sin duda el antecedente más cercano de nuestra obra: los autores

22.- Muy distinto, por ejemplo, a la indiferencia que caracterizará luego a las desamoradas de los libros de pastores y a las amadas mudas y ausentes de la lírica amatoria petrarquista. 
debieron conocerla bien, pues este best seller europeo se tradujo al castellano en Salamanca hacia $1496^{23}$. El enamorado Euríalo, tras quejarse en el mismo tono de Calisto, decide «buscar una alcayueta» (2001, p. 179) con la cual enviar una carta a su amada Lucrecia. La «alcayueta» ruega compasión por su cliente y la dama estalla súbitamente en ira. Vale observar la retórica llena de interrogaciones y exclamaciones exaltadas de Lucrecia, tan cercana a la de Melibea:

¿Qué osadía, muy malvada hembra, te traxo a mi casa?
¿Qué locura en mi presencia te consejo venir? ¿Tú las
casas de los nobles osas entrar y a las castas dueñas
tentar y los legítimos matrimonios turbar? ¡Malabés
me puedo refrenar de te arrastrar por essos cabellos y
la cara despedaçar! ¿Tú tienes atrevimiento de me traer
carta? ¿Tú me hablas? Si no oviesse de considerar lo que
a mi estado cumple más que lo que a ti conviene, yo
te haría tal juego que nunca de cartas de amores fueses
mensagera. Vete luego, hechizera. Lleva contigo tu carta;
aunque dámela, despedaçarla he y daré con ella en el
fuego. (2001, p. 181)

Obedeciendo a Coppina, hace trizas la carta, pisotea los pedazos y hasta los escupe. La respuesta de algunas damas puede ser tan furibunda que en una breve refundición de la historia de Piccolomini realizada por Luis de Lucena, en su Repetición de amores (escrita entre 1494 y 1499), la floja "alcayueta» acaba cayendo por las escaleras tras la extrema turbación sufrida: "Y ansí ella, con el temor que le puso la doncella, toda turbada, sin saber dó ponía los pies, dio consigo de rostros por una escalera do avía subido; de suerte que, tanto por el dolor que de la caída sentía, quanto por el daño mayor que esperava, tuvo más cuidado de salvar su vida, que de recordarse de la carta» (2001, p. 107).

Pero Coppina y Maddalena sabían muy bien que el requeridor y su servidora comprenderían a la perfección cuál es el verdadero significado de tal respuesta, cuya intención no es otra que cuidarse de las habladurías y guardar las apariencias ante la sociedad ${ }^{24}$. Ya he dicho que el «auctor» piensa al principio que la respuesta airada de Laureola es una buena señal

23.- Ver Matos (2018a). La obra fue escrita en latín en 1444. Cito siempre por la traducción castellana producida en Salamanca hacia 1496 (Piccolomini 2001).

24.- Por los ejemplos aducidos, no creo que la ira de Melibea, ni en el diálogo con Celestina ni al principio con Calisto, se deba a un interés consciente de los autores de presentar a Melibea colérica porque este temperamento fuera el más apropiado «para caracterizar a una mujer libidinosa que claudica rápidamente a los avances amorosos del caballero», como propone Lacarra (1997, p. 118) a la luz de la filosofía moral y del discurso médico de la época. De ser así, Laureola sería tan libidinosa como Melibea. No pongo en duda el temperamento colérico de Melibea ni su predisposición a la ira, la cual coincide con los argumentos filosóficos y médicos que expone Lacarra. Es solo que algunas de sus expresiones de ira, que a veces 
para la redención de Leriano. La «pública alcayueta» que tienta a Lucrecia, por ejemplo, sale gozosa a comunicarle la buena nueva a su cliente: «Alégrate, bienaventurado amador, de tu amiga más que amas eres amado. Agora no ovo lugar de responderte. Hallé turbada a Lucrecia y quando le di tu letra, muy alegre la recibió y mil vezes la besó. No dudes que luego te escrevirá» (2001, p. 81). Y hasta la alcahueta de la Repetición de amores de Lucena, pese a su turbación y lamentable caída — quién sabe si fue fingida - anuncia al enamorado: "Torna en ti, bienaventurado amador, que más a ti que tú a ella te ama aquella señora y porque estava triste no te pudo screvir. Dígote que quando te nonbré y le di tu carta, que se puso más alegre y por mil vezes besava el papel; y no dubdes que muy presto te aga respuesta» (2001, p. 107). Es cierto que la noticia llevada por las alcahuetas es falsa, pues no ha sido esa la respuesta recibida, pero no totalmente falsa: el significado de los distintos significantes es el mismo.

El rechazo airado implica, además, la necesidad de persistir en el servicio amoroso. Ya sabemos cuán desaconsejadas son las prisas. Ante este tipo de respuestas, Ovidio exhorta: "quod non rogat, optat, ut instes; / Insequere, et voti postmodo compos eris» ${ }^{25}$ (Ars amatoria, libro 1, vv. 485-486). Sabe que ella muestra una cosa, pero que desea otra. Por eso Gómez Manrique aconseja a un penado mortal cómo puede "cobrar esta señora» que desea: «Nunca por desgrado que della ayáis conoçido dexés de servirla, porque el mucho servir suele hazer por la persona (...) Y si con estas cosas non pudiéredes ablandar sus durezas, hazeos duro a sofrir y servilda lo mejor que pudiéredes por acá por lo llano, muriendo y llorando, que inposible es faltar galardón do no falta serviçio» ${ }^{26}$ (2001, pp. 79-80). «Femina quod prohibet cupit et vult sepe rogari», se lee en el Facetus, moribus et vita ${ }^{27}$ (apud Paolini 2010, p. 46).

Los autores, con todo, no se conforman con dar por sobreentendido el resultado de los procederes protocolares y permiten que Melibea y Celestina hagan gala de su fuerza retórica ${ }^{28}$. Celestina no se cae por las escaleras ni se marcha tras la respuesta airada de Melibea. Además, se desecha

suenan más disimuladas que auténticas, podrían responder más a la tradición amatoria que a tales argumentos eruditos.

25.- «desea lo que no te pide: que insistas en ello; persiste y verás en breve cumplidos tus deseos» (1995, p. 373).

26.- Para otra exitosa puesta en práctica de esta retórica de la seducción basada en la persistencia y auxiliada por una alcahueta, véase el anónimo "Tratado de amores» de fines del siglo xv editado por C. Gonzalo García en Cátedra et al. (2001, pp. 85-92).

27.- «La mujer desea lo que quiere tener lejos y muchas veces quiere que le ruegen».

28.- Coincido totalmente con Emilio de Miguel Martínez: «El propósito de Melibea [...] es permitir que la vieja pueda desarrollar sus artes, de modo que ella consiga escuchar la proposición que sospecha se le va a hacer, manteniendo en todo momento la conveniente simulación de que las cosas van avanzando con absoluta ingenuidad e inocencia por su parte. Y, como objetivo final, llegar al consentimiento pleno sin desdoro público de su honra» (2000, p. 40). 
la carta por «antidramática», como bien señala Lida (1962, p. 450). La joven, luego de amenazar de muerte a la alcahueta, continúa haciendo preguntas retóricas - las cuales nos suenan, una vez más, a un velado «dime más»-, hasta que accede a cumplir la demanda de la vieja. La criada Lucrecia sabe interpretar bien lo que se oculta detrás de las fórmulas: «YYa, ya: perdida es mi ama! Secretamente quiere que venga Celestina. Fraude hay. ¡Más le querrá dar que lo dicho!» (IV, p. 134). Y Melibea no repara en confirmar las sospechas: "Más haré por tu doliente, si menester fuere, en pago de lo sofrido» (IV, p. 135). Tampoco pierde tiempo Celestina y recurre a las leyes de Natura para justificar la atracción erótica entre hombres y mujeres esgrimiendo argumentos naturalistas para desleír enteramente la ira de la doncella: «Pues tú, señora, tenías ira con lo que sospechaste de mis palabras, no enemistad. Porque aunque fueran las que tú pensabas, en sí no eran malas, que cada día hay hombres penados por mujeres y mujeres por hombres, y esto obra la natura, y la natura ordenola Dios, y Dios no hizo cosa mala» (IV, p. 136). Al final, todo queda bien concertado.

\section{Melibea a solas}

La Lucrecia de la Historia de duobus amantibus de Piccolomini, que, como adelanté, es el antecedente literario más cercano de Melibea (Matos 2018a), descubre su pasión desde muy temprano en la obra. Se debate entre el deber y el deseo, conflicto que atenaza a todas las amadoras de la época, pues deben reprimir sus anhelos eróticos a fin de salvaguardar su honra y el buen nombre de su familia. "Nueva fuerça me tiene forçada: una cosa amonesta el amor y otra la honestidad» (2001, p. 173), dice en soledad. Prosigue con un soliloquio que revela la fuerza de la pasión amorosa desde la perspectiva femenina, hasta que concluye en detrimento de su honra: "¿Que pierda la fama? ¿Qué me haze el murmurar de los hombres que no oiré? Quien no cura de la honra sordo es» (p. 174), y se ampara en ejemplos clásicos: «Muchas otras de su voluntad hezieron esto mismo: fue Elena llevada, no la llevó Paris por fuerça. ¿Qué diré de Adriana y Medea? No deve ser reprehendido el que con muchos yerra» (2001, p. 174). El hecho de que estas abruptas confesiones figuren desde el inicio de la obra llevó a Lida a tildar de lasciva y deshonesta a Lucrecia en contraposición a la compleja "evolución interior» (1962, p. 453) de Melibea, y concluye que «la tortura moral y la pasión fogosa de Melibea son el polo opuesto de la falta de decoro y la lubricidad de Lucrecia» (1962, p. 452). Me permito diferir de Lida. Es verdad que existe cierta distancia entre el ímpetu que Lucrecia muestra al inicio de la obra y la manera en que los autores de la Tragicomedia presentan el proceso del enamoramiento de Melibea. Pero pienso que gran parte del distanciamiento se debe más a la construcción narrativa que a la naturaleza del erotismo vi- 
vido por los personajes. Joseph $\mathrm{T}$. Snow sugiere con acierto la genialidad artística de los autores al mantener encubierto el secreto amor de Melibea hasta el auto décimo (2017, p. 158). Es esto lo que potencia la tensión dramática y emotiva, y sin duda uno de los aspectos que constituyen la originalidad artística de La Celestina. Gracias a ello, es posible desarrollar con tanta profundidad los caracteres de los personajes, en especial la fuerza de un personaje tan imponente como Celestina, que, para poder realizar sus funciones a la altura de su fama, necesita sin duda una fuerte contrincante con quien presumir de sus aptitudes. Y, además, propicia la reflexión sobre la vivencia emocional dominada por el miedo y la duda que atenaza a las mujeres, que, debido a las rígidas normas sociales, no les es lícito dar rienda suelta a sus pulsiones eróticas. Los autores previos se conformaban con mencionar de pasada esta realidad, sin profundizar en el «convulso interior» - siguiendo la expresión de Emilio de Miguel Martínez (2000, p. 49) — de las enamoradas.

Melibea confiesa que ha quedado cautiva desde la primera vez en que ve a Calisto: «广Y no me fuera mejor conceder su petición y demanda ayer a Celestina, cuando de parte de aquel señor cuya vista me cativó me fue rogado, y contentarle a él y sanar a mí, que no venir por fuerza a descobrir mi llaga cuando no me sea agradecido, cuando ya, desconfiando de mi buena respuesta, haya puesto sus ojos en amor de otra?» (X, p. 219). Empezamos a notar su urgencia por dar riendas a su amor, contradictoria con el disimulo al que se ve obligada antes de ceder a sus tensiones interiores. Esta es la primera vez que escuchamos a Melibea hablar a solas, la primera vez que accedemos a su interioridad, la primera vez que no es necesario disimular ante nadie. Ruega a Dios la capacidad para seguir manteniendo encubierto su "amoroso deseo» (X, p. 220) un tiempo más. Pues enseguida descubrimos que el mal de Melibea — y, de paso, la pena de Calisto- se debe al moroso proceso que ha de seguir para alcanzar la plenitud erótica: «iOh género femíneo, encogido e frágile! ¿Por qué no fue también a las hembras concedido poder descobrir su congojoso y ardiente amor, como a los varones? Que ni Calisto viviera quejoso ni yo penada» (X, p. 220). La joven se queja ya sin ambages del código estricto que se ha visto obligada a seguir desde el principio, de todos los pasos que han de pasar antes de poder gozar de su amor. El propio Ovidio dejó muy claro que toda iniciativa amorosa debía partir del hombre y no de la mujer (Ars amatoria, libro I, vv. 705-722). Y el primer paso de esa iniciativa era el dado por Calisto y todos sus predecesores: mostrarse o fingirse enfermo para inspirar la compasión de la dama.

Antes de Melibea, en la comedia humanística Poliscena, la doncella Poliscena confiesa su pasión y su rebeldía desde el inicio de la obra. Lamenta que el "género femíneo" haya de vivir encerrado en casa y que no le sea permitido disfrutar de los placeres propios de la juventud, es decir, el gozo del amor, mientras que al varón sí. Su requeridor, sin embargo, resulta 
ser un donjuán que la ve como «una nueva ave que cazar» («nouum aucupium»), que la alcanza gracias a la retórica de la enfermedad de amor y al auxilio de una alcahueta. Al final, se conduce como un varón («viriliter»), es decir, la consigue por medio de la fuerza. Aunque la joven no termina tan bien parada en la historia, a excepción de que su madre intenta rezurcir el daño por lo legal, casándola con el galán, constituye un ejemplo de una doncella rebelde decidida a vivir su gozo y con una participación un poco más activa con respecto a otras protagonistas de textos temáticamente afines, aunque ciertamente no alcanza el grado de vitalidad que caracteriza a Melibea ${ }^{29}$.

Melibea se confiesa atenazada por el mismo apremio que otrora la Lucrecia piccolominiana - ni lasciva ni deshonesta- no pudiera encubrir por tanto tiempo. Asistimos entre bambalinas a la psique de amadoras menos librescas que reales, cuyas pulsiones íntimas no se acomodan adecuadamente a los códigos tradicionales. Aun así, cada una ha de seguir el papel que le corresponde a su "género femíneo" para salir airosa en su proceso de amores.

\section{Segundo encuentro entre Melibea y Celestina}

Le toca a Melibea concertar una cita con su amado Calisto. La urgencia convierte en tormento la dilación de la locuaz alcahueta. Comienzan a desdibujarse poco a poco las dotes persuasivas y hechiceriles de Celestina al pasar a ser una simple mediadora entre los amantes ${ }^{30}$. "Medianera de mi salud» la llama Melibea (X, p. 219), y así también la veía Calisto. " $\mathrm{O}$ h cómo me muero con tu dilatar! (...) ¡Agora toque en mi honra, agora dañe mi fama, agora lastime mi cuerpo, aunque sea romper mis carnes para sacar mi dolorido corazón, te doy mi fe ser segura, y si siento alivio, bien galardonada!», promete a Celestina tras confesar el encendido fuego que arde escondido en sus entrañas (X, p. 224). "Yo daré forma como tu deseo y el de Calisto sean en breve complidos", asegura la vieja (X, p. 229). Es ya cuestión de amar o morir (X, p. 230).

\section{9.- Remito a la edición bilingüe preparada por Antonio Arbea (1996-2000).}

30.- Opinión distinta pronuncian los que dan fe al poder de la magia. Como bien advierte Carlos Heusch (1992, pp. 21-22), la philocaptio constituye una "partie de l'univers culturel et érotologique de Rojas, "mancebo y estudiante" de Salamanque", junto con el amor hereos, la sexualidad médica, el naturalismo amoroso, etcétera, de modo que es necesario tomarlo en consideración al momento de evaluar los discursos en torno al amor presentes en la obra. Véase al respecto el fundamental ensayo de Peter Russell (1978) y complétese con Ana Vian Herrero (1990) y Patrizia Botta (1994). En cualquier caso, coincido con Heusch cuando afirma, junto con Pedro Cátedra, que nada obligaba a Rojas a introducir este aspecto, pues los idilios amorosos ya estaban más que justificados. 


\section{Esta noche, a las doce, en el jardín}

Por fin se ha hecho posible el alloquium entre los amantes. Melibea se cuida de guardar las apariencias, según lo exigen los códigos, y finge resistirse y velar por su honra:

La sobrada osadía de tus mensajes me ha forzado a haberte de hablar, señor Calisto, que habiendo de mí la pasada respuesta a tus razones, no sé qué piensas más sacar de mi amor de lo que entonces te mostré. Desvía estos vanos y locos pensamientos de ti, por que mi honra y persona estén sin detrimento de mala sospecha seguras. A eso fue aquí mi venida, a dar concierto en tu despedida y mi reposo. No quieras poner mi fama en la balanza de las lenguas maldicientes. (XII, p. 244)

Calisto ve venir la muerte ${ }^{31}$. Pero Melibea no está ya para más disimulos. Habiendo cumplido deprisa este último ritual, procede a ratificar el anuncio de la «solícita mensajera» (XII, p. 425) y se rinde a Calisto: «Limpia, señor, tus ojos; ordena de mí a tu voluntad». La frase está emparentada con la pronunciada por la Lucrecia piccolominiana: «Vencísteme: ya soy tuya, haz de mí a tu plazer» (2001, p. 188), así como con el «Faz tu talente» del Libro de buen amor (v. 631b) o el "De me fac modo uelle tuum» del Pamphilus de amore (v. 114) ${ }^{32}$. Calisto celebra haciendo gala de su elocuencia, para muchos desgastada, y Melibea reitera su entrega absoluta: "Y aunque muchos días he pugnado por lo disimular, (...) te suplico ordenes y dispongas de mi persona según querrás» (XII, p. 246). Para bien o para mal, se cumple la premonición de Celestina: "Coxquillosicas son todas, mas después que una vez consienten la silla en el envés del lomo, nunca querrían holgar (...) Catívanse del primer abrazo, ruegan a quien rogó, penan por el penado, hácense siervas de quien eras señoras, dejan el mando y son mandadas, rompen pareces, abren ventanas, fingen enfermedades» (III, pp. 102-103).

Si fue Melibea la primera en hablar de "deleite» en el primer auto cuando Calisto le confesaba su «secreto dolor» y celebraba la promesa de "galardón", también es la primera en explicitar el deseo de gozar tal deleite. No deja de ser curioso que veamos a la otrora elegante dama descender a un lenguaje más coloquial, incluso cuasi vulgar por excesivamente abierto, que más asociaríamos con Calisto que con ella. Es como si fuéramos conociendo poco a poco cómo es de veras Melibea: «Las puertas impiden

31.- El mismo esquema se produce en la Historia de duobus amantibus, pero mediante epístolas. Ver Matos (2018a).

32.- Me ocupo de esta frase afortunada en un trabajo de futura aparición: “"Faz tu talente”: apostillas a una frase deshonesta». 
nuestro gozo, las cuales yo maldigo y sus fuertes cerrojos y mis flacas fuerzas, que ni tú estarías quejoso ni yo descontenta». Se intensifican las ansias de saltar a la fase del contactus, tanto que Calisto propone con indiscreción quebrar las puertas, lo cual suscita ciertas reminiscencias del violento aporreo a la puerta por parte de Pánfilo y don Melón, indicio de su desmedida urgencia erótica, solo que es la dama esta vez quien toma la voz cantante y comunica con desenfado su deseo de avanzar en el proceso erótico. Y quien concierta la próxima cita: mañana, a la misma hora, en el huerto ${ }^{33}$.

\section{Recapitulemos}

Hasta aquí, hemos acompañado a los dos amantes en la primera parte de su proceso de amores. Calisto confiesa su mal a quien lo tiene penado, sirviéndose de un discurso cortesano un tanto excesivo, pero adecuado a los códigos esperados. Melibea, al escuchar el atrevimiento de quien atenta contra su honra, responde airada, como también era de esperarse, aunque no sin haber lanzado señales ambiguas que avivan y destruyen a un tiempo las esperanzas de Calisto. El penado, asesorado por su criado, recurre a una medianera para conseguir el favor de su dama, a fin de remediar su muerte, pues sabe que sin su intervención no podría llegar a más. La alcahueta visita a Melibea y la doncella se enfurece y la amenaza iracunda, como también era de esperar. Pero solo es por guardar las apariencias, pues sus exclamaciones e interrogaciones sobresaltadas velan mal su interés por saber más de su pretendiente. Entre vaivenes retóricos, la joven sabe cómo acceder a las peticiones de la vieja, quien se retira en volandas, meneando sus faldas, a comunicarle la buena nueva a su cliente. Calisto se entera por fin de que lo que significan los ásperos desvíos y desdenes de las «encerradas doncellas» al principio de los requerimientos de amor. Es lo que preceptúa el protocolo, que "la hacen forzosamente confesar el contrario de lo que sienten». Melibea, a solas, lamenta que el proceso tenga que ser así, que no le sea posible asumir una parte más activa por ser mujer y que tenga que esperar a que Calisto, que parece principiante en estas lides, mueva las fichas oportunas. Muy a su pesar, se ve obligada a disimular su "amoroso deseo" por un tiempo para no faltar a las normas del decoro. Aunque no por mucho más: una vez regresa Celestina, le descubre su pasión y concierta con urgencia una cita con su enamorado. Llegado el día, cumple superficialmente con el precepto de resistirse y velar por su fama, y asume enseguida las riendas de lo que resta para ser feliz.

33.- Coincido con Emilio de Miguel Martínez: «Lectores atentos de todo el proceso, tenemos la seguridad de que ha sido Melibea la que, desde luego con enorme tensión, lucha interior y zozobra, ha marcado tiempos y límites; la que ha impuesto barreras y ritmos. La que ha decidido, en definitiva, dónde, cómo, cuánto y cuándo» (2000, p. 55). 
Declara abiertamente su deseo de gozo, mientras Calisto se pierde en circunloquios, y concierta una nueva cita, de noche, a las doce, en el huerto.

Ha llegado el momento de acceder a la última fase del amor. Todos los caminos conducen a los tálamos de Venus.

\section{Mille modi Veneris. Melibea y Calisto en los tálamos de Venus}

Gracias daba a Venus uno de sus soldados tras la exitosa realización de la plenitud erótica. Se trata de un desenfadado goliardo que, tras una larga lucha, pudo alcanzar por fin la última y mejor meta del amor:

$$
\begin{aligned}
& \text { Visu, colloquio, } \\
& \text { contactu, basio, } \\
& \text { frui virgo dederat, } \\
& \text { sed aberat } \\
& \text { linea posterior } \\
& \text { et melior } \\
& \text { amori. }{ }^{4}
\end{aligned}
$$

La doncella le había consentido gozar cuatro de los cinco gradus amoris, pero se negaba en redondo a otorgar la última y mejor meta del amor: el factum. Pero el enamorado no se conforma con tan poco. Cada vez se acerca más a su meta. Ella se resiste. Con tierno llanto le suplica que esté quedo. Él le ruega y la besa, mas solo logra avivar el llanto de la doncella. A ella la atenaza la duda, pues teme por su honra. Sus lágrimas, sin embargo, atizan cada vez más la llama de amor del varón. «Delibuta lacrimis / oscula plus sapiunt» («Perfumados de lágrimas, los besos son más sabrosos»). El llanto se transforma en sollozos desbordados. Los ruegos del enamorado no logran mitigarlos. Él suma besos, suma ruegos; ella, llanto. La doncella permanece sorda a las instancias. El enamorado, harto audaz, recurre a la fuerza:

Vis nimis audax infero, hec ungue sevit aspero, comas vellit, vim repellit

strenu, sese plicat et intricat genua, ne ianua

34.- «Ver, hablar, tocar, besar, la moza me había otorgado gozarlo; pero aún distaba la última y mejor meta del amor». 


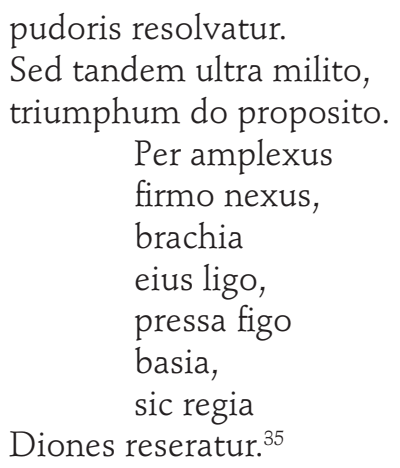

Ella le clava sus uñas, lo tira del pelo, demuestra su enfado, cruza sus piernas protegiendo las puertas del pudor. Pero él no se rinde. Los brevísimos versos se suceden tan raudos que nos permiten intuir la celeridad de los impetuosos modos amorosos. Y de súbito, todo ha terminado. El poeta amante nos confiesa con enorme desenfado: «Res utrique placuit». La contienda ha placido a ambos. Los reproches devienen besos de miel y ambos terminan sonrientes, agotados, adormecidos. En especial ella:

Et subridens tremulis
semiclausis oculis,
veluti sub anxio
suspirio
sopita. ${ }^{36}$

No sería exagerado afirmar que hemos aprendido, a través de los deliciosos versos del carmen Buranum ${ }^{37}$, el arte de amar más popularizado en la Edad Media. Repetido una y otra vez en las lenguas más diversas, la escena tendría larga vida en la España de Fernando de Rojas. No son otros los modos eróticos empleados por Calisto cada una de las noches que asiste al huerto de Melibea. Y ella lo sabe muy bien. Pero no vayamos tan deprisa.

Veneris in thalamos ducunt omnes vie ${ }^{38}$. Cumple que acompañemos a los jóvenes amantes en sus aventuras eróticas. Melibea ha concertado una cita con su enamorado tras verse impedida de vivir su gozo debido a las «molestas y enojosas puertas» que la separan de Calisto el día de su allo-

35.- «Harto audaz, recurro a la fuerza: ella me clava las uñas aguzadas, me tira del pelo, me rechaza llena de coraje; y se dobla y cruza las rodillas, para que no se quiebre la puerta del pudor. Pero llevo la lucha adelante, lo pongo todo al servicio del triunfo. Con abrazos afirmo el vínculo y le ligo los brazos, la cubro de besos: así se abre el real de Dione».

36.- «Y sonriente, trémulos los ojos medio cerrados, en un suspiro como de inquietud, se adormece».

37.- El poema completo, que inicia con el verso "Grates ago Veneri», se encuentra en las páginas 124-131 de la edición de los Carmina Burana manejada (1978).

38.- Cito dos versos del carmen Buranum que empieza «Estuans intrinsecus» (pp. 272-289): «Todos los caminos llevan a los tálamos de Venus». 
quium. A la noche siguiente, Calisto salta las paredes y accede al ameno huerto en que aguarda ansiosa Melibea junto a su criada Lucrecia. Por fin se hace posible avanzar al contactus. Enseguida se lanza en pos de su amada. Sus impúdicas manos no logran estarse quedas. No hay ya barrera que impida seguir avanzando hasta la linea posterior et melior. Excepto cierta resistencia que aún opone la doncella: «No quieras perderme por tan breve deleite y en tan poco espacio, que las mal hechas cosas, después de cometidas, más presto se pueden reprehender que enmendar. Goza de lo que yo gozo (...) Está quedo, señor mío. Bástete, pues ya soy tuya, gozar de lo esterior, desto que es propio fruto de amadores; no me quieras robar el mayor don que la natura me ha dado" (XIV, p. 273). El fuego que abrasa a Calisto es demasiado conflagrante y no es posible mayor dilación. Y en muy poco tiempo, todo termina. Poco puede saber el lector sobre los modos empleados por Calisto para culminar esta experiencia erótica, pero sí sabemos que Melibea se resistió, como otrora lo hiciera la doncella del carmen Buranum, y, finalmente, fue vencida.

Pero los autores sabrán revelarle muchos más datos al lector en el segundo encuentro de los amantes, acaso complaciendo a los rijosos lectores que tanto lo importunaran para que «se alargase en el proceso de su deleite destos amantes» (Prólogo, p. 21).

Ha pasado un mes. Melibea espera a su amado una noche más en su exultante tálamo venéreo. De gozo se deshace y con su «ronca voz de cisne» comienza a entonar cancioncillas eróticas junto a su criada, irradiando su gozo infinito por el ameno espacio nocturno. Llega Calisto, un poco retrasado, y todo se goza el huerto con su venida. Y, una vez más, las impúdicas manos no logran estarse quedas. Se destempla la voz de la joven ante la rapidez con que Calisto comienza a despojarla de sus vestidos. "Desapareciose el deseo», confiesa Melibea, debido a las "mañas» de su amador. Una vez más, la joven confiesa su disgusto ante el proceder impulsivo de su amante. "Mándalas estar sosegadas y dejar su enojoso uso y conversación incomportable. Cata, ángel mío, que así como me es agradable tu vista sosegada, me es enojoso tu riguroso trato. Tus honestas burlas me dan placer, tus deshonestas manos me fatigan cuando pasan de la razón. Deja estar mis ropas en su lugar...» (XIX, p. 321). Podríamos pensar en la preceptiva erótica tradicional, que - como tendremos ocasión de explorar con más detalle- manda a la mujer a resistirse a fin de «fincar más desculpada» — por decirlo con un verso de Juan Ruiz-y a un tiempo avivar el deseo amoroso del varón ("Delibuta lacrimis / oscula plus sapiunt»). Sin embargo, a la altura de un mes de encuentros gozosos, hay algo que parece no encajar bien y que nos persuade de estar ante una situación distinta. Ya Melibea ha perdido su virginidad, por lo que no es del todo necesaria su resistencia obligada — aunque tampoco sería la única no-virgen que recurre a tales remilgos-, y espera con ansias a su amado con el fin exclusivo de gozar los placeres de Venus. Adverti- 
mos, en cambio, que el "riguroso trato» de Calisto es incongruente con las «honestas burlas» deseadas por Melibea. Es cierto que «honestas» nos suena un poco a resistencia pudorosa y que podría querer proponer un divertirse sin llegar a los extremos últimos del deleite venéreo. Sin embargo, «burlas» parece contradecir el calificativo que le precede y alinearse junto con las cantilenas eróticas con que muy poco antes se recreaba la muchacha en compañía de su criada. En efecto, «burla» fue empleado en la época como equivalente a los latinos ludo y lusus, todos con un claro sentido sexual, pertenecientes al campo semántico del iocus ${ }^{39}$. El irónico oxímoron «honestas burlas» parecería apuntar más a un rechazo de las toscas «burlas» de Calisto que a un remilgo pudibundo. No es difícil sospechar que la joven desea retrasar el acto con mil juegos y burlas para gozarlo aún más: acaso lo que modernamente se denomina como el foreplay. Melibea se encarga de dejarlo muy claro enseguida: «Holguemos y burlemos de otros mil modos que yo te mostraré; no me destroces ni maltrates como sueles» (XIX, p. 321). De súbito, la joven propone a viva voz y en pleno factum unos novedosos «mil modos» alternos de hacer el amor, distintos a los que puede ofrecerle su desbocado amante. Es preciso anotar que esto ya no forma parte de los manuales teóricos al uso que los protagonistas habían seguido más o menos fielmente. Vienen al recuerdo, en cambio, los "mille ioci Veneris» que celebrara Ovidio en su Ars amatoria (III, v. 787) —olvidados, como veremos, durante los siglos medios-y que entran en flagrante contradicción con el "riguroso trato» de Calisto. Melibea, con sus "mil modos», parece alinearse con el más liberal Ovidio. Aún más: no son pocos los códices del texto ovidiano que leen "mille modi Veneris» en lugar de «ioci» ${ }^{40}$, frase que parece calcar de algún modo Melibea. Y es que para el poeta latino, sin duda el más famoso magister amoris de las letras occidentales, los modi no eran otra cosa que las maneras o posiciones sexuales (también figurae o schemata) ${ }^{41}$. Así

39.- Para el sentido erótico de los vocablos latinos, véanse Adams (1982, pp. 161-163) y Montero-Cartelle (1991, pp. 187-189). El empleo de los equivalentes castellanos puede verse en los numerosos ejemplos recogidos en la antología de Alzieu et al. (2000). El siguiente pasaje de una traducción anónima del Tirant lo Blanc, publicada en 1511, lo ilustra perfectamente: "Tirante no curó de las palabras de la Princesa, sino que se allegó a ella y tomóla en los braços y besóla muchas vezes en los pechos y en los ojos y la boca. Y como las donzellas vieron que Tirante así jugava con su señora, todas estubieron quedas; y como él le ponía la mano debaxo de las haldas, eran todas ellas en su ayuda. Y estando en estos juegos y burlas sintieron que la Emperatriz venia a ver qué hazía su hija, y con los juegos no la sintieron hasta que llegó a la puerta de la cámara» (1974, p. 77; énfasis mío).

40.- De ello da cuenta Adams (1982, p. 161). La edición latina manejada opta por «modi» en vez de «ioci».

41.- Para el sentido erótico de modus, véase Thesaurus linguae latinae, sub voce, p. 1267, líneas 57-63. La frase ovidiana aparece también en Amores 3,14, v. 25: «inque modos Venerem mille figuret amor» ("y que la pasión invente mil posturas para amar»). Este sentido de modus aparece varias veces en Ovidio, como Amores 3, 7, v. 64: «quos ego non finxi disposuique modos» ("¿qué posturas no tenía yo imaginadas y planeadas?»); y Ars amatoria, libro 2, vv. 679-680: «Utque ve- 
pues, los «mil modos» propuestos por Melibea, sus «mille modi vel ioci Veneris», nos permiten interpretar su queja y su reclamo no solo como un "falso defenderse», sino también como una propuesta auténtica de modos alternos de hacer el amor, acaso un preludio más deleitable y moroso que las bruscas maneras de Calisto, y modos para la consecución de los cuales ella se siente capaz de aleccionar a su amador.

La respuesta de Calisto, con todo, no puede ser más atroz: «Señora, el que quiere comer el ave, quita primero las plumas». Es preciso decir que, con frases como esta, el joven no sigue ya la espesa retórica cortesana heredada. Parecería, asimismo, que hay algo palpitante, menos libresco, en Melibea, algo que no es capaz de comprender su enamorado. Poco a poco se deslíe la espesa tradición erótica occidental y van surgiendo personajes palpitantes que parecerían actuar fuera del convencionalismo del arte. La joven, ante la desenfrenada urgencia amorosa de Calisto, que acorta sin remedio la duración de su deleite ${ }^{42}$, se atreve a reclamar su derecho al placer erótico. Inconforme con los modos corteses - o descortesesheredados, se nos confiesa deseosa de experimentar otros «mil modos» más delicados y lentos que la flagrante rudeza de Calisto. Y al hacerlo, para desconcierto nuestro, se declara de súbito una experta en el arte de amar. Y en un arte de amar conforme a su propio código femenino, el cual parece que ignoraran todos los teóricos europeos al uso.

Ya nos ocuparemos de atender la "originalidad» erótica de Melibea. Los modos de Calisto, cumple decirlo, no son los de un inexperto en amores a ojos de un lector de la época. El joven no hace sino seguir un arte de amar consagrado por siglos de uso en Europa, sin duda el ars amatoria más popular de la Edad Media. Cumple, pues, que nos detengamos a explorar la tradición erótica con la que hace escuela Calisto, aquella con la que, de la mano del desenfadado clérigo vagante, iniciábamos este apartado.

\section{El ars amatoria más popular de la Edad Media}

Qui querit coitum, si vim post oscula differt,

Rusticus est, numquam dignus amore magis. (vv. 301-302)

Así de claro se explicita en el manual de cortesía del siglo XII conocido como Facetus, moribus et vita; es decir: quien quiere el coito, si después de los besos posterga el uso de la fuerza, es un villano y no es digno de amor

lis, venerem iungunt per mille figuras: / invenit plures nulla tabella modos» ("a tu gusto hacen el amor en mil posturas: ninguna pintura enseña más modalidades»). La frase «mille modis» también aparece en otros autores latinos, como en el epigrama 67 de Marcial.

42.- Alan D. Deyermond destaca la rapidez brutal de la consumación sexual dirigida por Calisto y comenta que «no se trata de una consumación alegre, ni siquiera de una seducción amorosa, sino casi de una violación» (2008, p. 46). Lo mismo opina José M. Martínez Torrejón (2005). 
nunca más ${ }^{43}$. Este sumario de buenas maneras, que formaba parte de la educación integral de todo joven elegante, exponía con lujo de detalles el proceder que el hombre debía seguir para triunfar en sus experiencias amorosas, incluyendo ciertos pormenores del factum ${ }^{44}$. No difiere de lo que hemos visto ya en la primera parte. Para conseguir su fin deseado, el amante debe buscarse una mensajera que lo ayude a persuadir a la dama de que acepte a concederle una cita a solas. Debe ser linsonjera y pertinaz, capaz de tolerar e interpretar los airados desdenes de la doncella. La persistencia acabará por vencer a la más dura doncella del mismo modo que una gota continua es capaz de horadar la dura piedra.

Cuando llegue por fin el día del encuentro, así debe conducirse el joven elegante si desea estar a la altura de las expectativas y llegar triunfante a la meta última del amor:

Si quoque, dum loquitur, jam femina laude movetur, Leviter hanc tangat vestibus ipse super.

Non adeo mentem rigidam tenet ulla puella, Ut, si tangatur, risus in ore vacet.

Si fugiat tactum, subridens forcius angat,

Vel digitis coxas comprimat atque latus.

Sed tamen in cunctis placidus modus est adhibendus,

Nam sine mensura nil valet esse bonum.

Curet ut insolitam faciat gaudere puellam,

Dulcius exorans oscula grata petat.

Spondeat et juret quod nil petet amplius ipse,

Nam bene sufficiunt talia dona peti.

Si negat illa quidem dare talia, forte minando,

Hec eadem precibus non minus ipse petat.

Sed quia sic multis verecundia sepius obstait,

Ut quoque conjugibus basia justa negent,

Jungere non timeat violenter bracchia collo,

Et prompte capiat quod negat illa dare.

Tunc non simpliciter jugantur grata labella,

Sed teneant longas basia pressa moras.

Mobilis interea stringat manus una mamillas,

Et femur et venter sentiat inde vicem.

Sic postquam ludens fuerit calefactus uterque,

Vestibus ejectis, crura levare decet.

Vim faciat iuvenis, quamvis nimis illa repugnet,

Nam si desistat, mente puella dolet.

43.- He citado por Devid Paolini (2010, p. 46), quien recoge algunos de los ejemplos que aduciré a continuación.

44.- Véase el ensayo de Martínez Torrejón (1987), quien ofrece más detalles sobre este manual y señala las coincidencias con el Libro de buen amor. 
Expectat potius luctando femina vinci,

Quam velit, ut meretrix, crimina sponte pati. (vv. 271-298) ${ }^{45}$

No cabe duda de que estamos ante un auténtico ars amandi medieval cuyas lecciones no son sino la teorización sistemática de los modos que tanto pluguieran al clérigo vagante y a su amada. Un verdadero amante no puede conformarse con besos, sino que, como buen miles Veneris, siempre ha de luchar hasta llegar a la linea posterior et melior. La insolita puella, es decir, la doncella que está poco acostumbrada a estas lides, se resistirá, hará todo lo posible por desasirse de las manos de su amador. Pero el varón educado sabe que en ese momento ha de recurrir a la fuerza, lo cual también agrada a la joven, pues, de no hacerlo, - es decir, de desistir de la contienda ante la oposición de la doncella - ella terminaría insatisfecha y triste, y él sería tenido por apocado. El dictum que se sigue de esta exposición erotológica es rotundo:

Qui querit coitum, si vim post oscula differt, Rusticus est, numquam dignus amore magis.

La violencia viril se convierte en un verdadero sine qua non del acto amoroso. Pero los remilgos y el empleo de la fuerza tienen, en principio, una explicación práctica, más allá del deleite que pueda producir la contienda — que no será poco, según habremos de seguir constatando-: así la doncella puede aminorar la culpa de haber perdido su doncellez fuera de los nudos matrimoniales, o, al menos, guardar las apariencias. Se libra de ser tildada de meretrix o de mujer fácil. Y "carius habetur quod pluribus est laboribus acquisitum quam quod sollicitudine modica possidetur», recuerda Andreas Capellanus en su tratado sobre el amor (1985, p. 88). No otra cosa le anticipa doña Venus al arcipreste de Hita al adoctrinarlo sobre el «fecho» (factum):

45.- «Y así, mientras el hombre le habla y solicita la mujer con alabanzas, empiece a tocarla dulcemente encima del vestido. Ninguna doncella tiene la mente tan firme que si la tocan no tenga la sonrisa en los labios. Si evita el contacto, con sonrisas le apriete con más fuerza la cadera y el flanco. De todos modos, en todos los movimientos hay que utilizar una cierta medida; de hecho, sin medida, ninguna buena cosa puede realizarse. [El joven] tiene que preocuparse de divertir a la doncella que no está acostumbrada a eso, e implorando dulcemente le pida gratos besos. Le prometa y jure que él mismo no pide nada más. De hecho, tales dones son más que suficientes para que se pidan. Si ella no quiere dar tales dones y se enoja, el joven no desista de su intento y continúe a pedirlos con más ruegos. Pero, como muy a menudo el recato angustia a muchas, tanto que se niegan también a los maridos los legítimos besos, el joven no tema de atacarle con fuerza los brazos al cuello, así que rápidamente obtenga con ímpetu lo que ella no quiere dar. Si luego unirá sus labios a tu boca, entonces los besos lentos tengan largas demoras. Mientras tanto una mano libre apriete los senos, y la pierna y el vientre advertirán gracias a eso el contracambio. Cuando los dos así jugando estarán excitados, se quiten los vestidos, y será necesario levantar las piernas. El joven haga fuerza, por cuanto ella se oponga; porque si se parara, la doncella probaría un gran dolor en el alma. La mujer espera que la ganen luchando más que admitir espontáneamente sus culpas, como una meretriz». He citado, tanto el original como la traducción, por Devid Paolini (2010, p. 46). 
Por mejor tiene la dueña de ser un poco forçada que decir: "Faz tu talente», como dervergonçada; con poquilla de fuerça finca más desculpada: en todas las animalias ésta es cosa provada.

Todas [las] fenbras han en sí estas maneras: al comienço del fecho sienpre son referteras, muestran que tienen saña e [que] son regateras, amenazan mas non fieren; en çelo son arteras.

Maguer que faze bramuras la dueña que se doñea, nunca el buen doñeador por esto enfaronea: la muger bien sañuda e qu'el omne bien guerrea, los doñeos la vençen por muy brava que sea.

El miedo e la vergüença faze a las mugeres non fazer lo que quieren, bien como tú lo quieres: non finca por non querer; cada que podrieres toma de la dueña lo que d'ella quisieres. (estrofas 631-634)

Ninguna mujer con vergüenza se entregaría fácilmente a su pretendiente sin oponer ninguna resistencia. "Con poquilla de fuerça finca más desculpada». "Lásciati sforzare», ordena Coppina a Maddalena en el Specchio d'amore (1912, p. 283). Más que un consejo práctico, este proceder erótico femenino se convierte en regla en casi todos los lechos venéreos de la literatura medieval hispánica, tanto que Juan Rodríguez del Padrón, en su Triunfo de las donas, da cuenta de cómo la mujer hace el amor «en son de forçada, el onbre en son de forçador» (1982, p. 222) a fin de demostrar la honestidad femenina.

Tales preceptos, de tan amplia difusión sobre todo a partir del siglo XII, se remontan nada menos que a las lecciones que dictara Ovidio a sus alumnos varones:

Oscula qui sumpsit, si non et cetera sumet,

Haec quoque, quae data sunt, perdere dignus erit.

Quantum defuerat pleno post oscula voto ?

Ei mihi, rusticitas, non pudor ille fuit.

Vim licet appelles : grata est vis ista puellis :

Quod iuvat, invitae saepe dedisse volunt.

Quaecumque est veneris subita violata rapina,

Gaudet, et inprobitas muneris instar habet.

At quae cum posset cogi, non tacta recessit,

Ut simulet vultu gaudia, tristis erit.

(Ars amatoria I, vv. 669-678) ${ }^{46}$

46.- «El que ha conseguido besos y no ha conseguido también lo demás, será digno de perder incluso lo que se le dio. ¿Cuánto te habría faltado, después de los besos, para colmar tu deseo? ¡Ay de mí!, eso ha sido necedad y no vergüenza. Aunque le des el nombre de violencia: a las mujeres les gusta esa clase de violencia; lo que les produce placer, desean darlo muchas veces obligadas por la fuerza. Todas se alegran de haber sido violadas en un arrebato 
Magister dixit. Una vez más, el verdadero amante no puede conformarse con besos y abrazos, sino que ha de llegar hasta el último grado del amor. Si no, sería tenido por apocado y nunca más digno de amor. Para ello, es imprescindible el empleo de la fuerza. Gran chasco se llevaría la dama si faltara este ingrediente esencial en el juego amoroso y más aún si por ello no pudiera alcanzar la última y mejor meta del amor. Es preciso advertir, con todo, que los consejos ovidianos no se limitan a estos modos violentos, descritos en apenas unos pocos versos de su gran manual erótico. Contrario a los raudos y brevísimos versos a través de los cuales recreaba el goliardo su encuentro sexual con su enamorada, Ovidio insiste en la importancia de dilatar los placeres venéreos lo más posible:

Crede mihi, non est veneris properanda voluptas, Sed sensim tarda prolicienda mora. (Ars II, vv. 717-718) ${ }^{47}$

El erotólogo latino ofrece además consejos relativos a posiciones (modi) y aconseja varias veces la consecución del orgasmo mutuo, aspectos completamente ignorados por los refundidores medievales:

Ad metam properate simul : tum plena voluptas,

Cum pariter victi femina virque iacent. (Ars II, vv. 727-728)

Sentiat ex imis venerem resoluta medullis

Femina, et ex aequo res iuvet illa duos. (Ars III, vv. 793-794) 48 $^{48}$

Es cierto que el goliardo nos asegura que "res utrique placuit», pero también es cierto que el Ars de Ovidio, en manos de los erotólogos medievales, va quedando despojado de la creatividad tocante al coito (los mille modi Veneris) y va dando paso a un tipo de seducción violenta y rauda que redunda en el «riguroso trato» que acabaría por cansar a Melibea a la altura de un mes de encuentros con Calisto ${ }^{49}$.

Con todo, no todas las jóvenes acabaron tan sonrientes al verse víctimas de este modo de seducción violenta. Me refiero en especial a la joven

imprevisto de pasión y consideran como un regalo esa desvergüenza. Por el contrario la que, pudiendo haber sido forzada, se retira intacta, aunque finja alegría en su rostro, estará triste» (1995, pp. 382-383).

47.- «Créeme: no hay que apresurar el placer de Venus, sino retrasarlo poco a poco con morosa lentitud» (1995, p. 422).

48.- "Llegad a la meta al mismo tiempo; entonces el placer es completo: cuando la mujer y el hombre yacen después de haber languidecido a la par» (1995, p. 422); "Que la mujer sienta a Venus, satisfecha desde lo hondo de sus tuétanos, y que la cosa agrade por igual a ambos» (1995, pp. 462-463).

49.- Me pregunto a qué se deberá este «recorte» tan triste del más liberal Ovidio. Sospecho que podría deberse a los estrictos códigos del honor propios de la época, que dictan cómo la mujer debe ser siempre recatada y honesta. Ya citaba cómo Rodríguez del Padrón defendía la honestidad femenina precisamente recurriendo a este argumento: la mujer hace el amor «en son de forçada, el onbre en son de forçador». 
protagonista del Pamphilus sive de arte amandi. El título de la obra nos sitúa de inmediato en el mismo ámbito de la tratadística amatoria al que pertenecen los textos ovidianos y manuales como el Facetus. Asistimos a la puesta en práctica de los consejos expuestos.

Recordemos brevemente la historia. Herido de amores, Pánfilo suspira por la bella Galatea, una joven virgen de clase superior a él. Al borde de la muerte, el penado recurre a Venus, quien le dicta todo un ars amandi, basado en el fingimiento y en la persistencia, a fin de que logre salvarse de la muerte que lo amenaza si no obtiene el remedio. Para lograr sus propósitos venéreos, se precisa, además, de la intervención de una medianera o alcahueta. Pánfilo continúa sus corteses lamentos, del mismo modo que Calisto, doliéndose por la insatisfacción de su deseo y dejando constancia de los síntomas que lo aquejan. Tras una rápida conversación con la causante de su muerte, consigue que Galatea, a pesar de su inicial rechazo —obligado, si se quiere-, consienta futuros abrazos y besos, es decir, cuatro de los cinco gradus amoris. Pero ningún verdadero amante ha de conformarse con tan poco. Deseoso de más, el amante acude a la vieja medianera y, tras hacer negocios, esta parte a casa de la doncella. Bajo la máscara del fingimiento, asistimos el diálogo entre ambas mujeres y descubrimos que Galatea también se muere por encontrarse con su requeridor, pero la detienen la duda y el temor de perder su honra. Con todo, no es muy difícil de convencer. Lo advertía doña Venus: «la muger que está dubdando, ligera es de aver» (estrofa 642). Muy pronto va a la casa de la vieja, donde se encuentra con su solicitante $y$, enseguida, se consuma el insospechado quinto grado del amor siguiendo al pie de la letra los modos eróticos expuestos. Hasta aquí, no hay gran sorpresa: la historia bien podría pasar por ovidiana o por goliardesca. Pero muy pronto surge el desconcierto: Galatea nunca parece disfrutar de este quinto grado, pese a la impecable realización del código amatorio:

Pamphile, tolle manus!... te frustra nempe fatigas!

Nil ualet iste labor!... Quot petis esse nequit!...

Pamphile, tolle manus!... Male nunc offendis amicam!... Iamque redibit anus: Pamphile, tolle manus!...

Heu michi! Quam paruas habet omnis femina uires!

Quam leuiter nostras uincis utrasque manus!...

Pamphile! Nostra tuo cur pectore pectora ledis?...

Quod me sic tractas..., est scelus atque nephas!...

Desine! Clamabo!... Quid agis? Male detegor a te!...

Perfida, me miseram, quanto redibit anus?

Surge, precor!... Nostras audit uicinia lites!...

Que tibi me credit non bene fecit anus!...

Vlterius tecum me non locus iste tenebit

Nec me decipiet, ut modo fecit, anus!... 


\section{Huius uictor eris facti, licet ipsa relucter, Sed tamen inter nos rumpitur omnis amor! (vv. 681-696) ${ }^{50}$}

Por un instante, pensamos que se trata del convencional rechazo, de esa lucha lúdica que tanto aviva la llama de amor del varón, mas las imprecaciones de la joven revelan un disgusto de tal magnitud que nos persuade de no estar ante un fingimiento. Galatea nunca muda su cara compungida. Sus lágrimas, que para el goliardo perfumaban los besos y los hacían más sabrosos, no desaparecen tras el factum. No es posible para Pánfilo, de modo alguno, pronunciar "Res utrique placuit», ni acabar adormecido y sonriente en el regazo de su amada. La joven no parece haber disfrutado ni un segundo del acto amoroso - bastante breve, por cierto-y acusa con gran enojo el crimen del cual ha sido víctima. Todo apunta más bien a lo que hoy llamaríamos una violación técnica. La insolita puella, al parecer, no actuaba tan a conciencia ${ }^{51}$.

50.- «¡Pánfilo, quítame las manos de encima!... ¡te estás cansando en vano! ¡De nada te sirve tu acoso!... ¡Lo que pretendes... no puede ser! ¡Pánfilo, retira esas manos!... ¡De mala manera estás ofendiendo a una amiga!... ¡A punto está de volver la vieja! ¡Pánfilo, retira esas manos!... ¡Ay de mí! ¡Qué escasas fuerzas tiene una mujer! ¡Con qué facilidad neutralizas mis dos manos!... ¡Pánfilo! ¿Por qué aplastas mis pechos con tu pecho?... Manosearme así... ¡es un crimen, una profanación!... ¡Déjame estar... o me pongo a chillar!... ¿Qué haces? ¡Es malo que me destapes!... ¡Ay, pobre de mí! ¿Cuándo volverá esa vieja traidora? ¡Levántate, por favor!... ¡El vecindario está oyendo nuestras voces!... ¡La vieja que me ha entregado a ti no ha obrado nada bien!... ¡Nunca más me ha de volver a encerrar contigo en este recinto, ni la vieja volverá a engañarme como acaba de hacerlo!... ¡Saldrás vencedor en este asalto a pesar de mi resistencia, pero el amor entre nosotros queda definitivamente roto!» Cito por la edición y traducción de Lisardo Rubio y Tomás González Rolán (1977: pp. 167-169).

51.- Resulta interesante la resolución del caso ofrecida tanto por la Anus como por Trotaconventos en el Libro de buen amor: el matrimonio. Los personajes recurren a términos legales para resolver la incómoda situación hasta que la vieja dictamina: «Hec tua sit coniux! Vir sit et iste tuus» (v. 778). Esta era precisamente la solución que proponían los decretos eclesiásticos que seguían el Decreto de Graciano del siglo XII: el raptor debe casarse con la víctima si esta así lo consiente (Gravdal 1991, p. 8). Galatea se muestra interesada en ello, aunque primero desea el consentimiento de sus padres. La vieja, sin embargo, es consciente de la imposibilidad de tal petición y busca cómo evadirla, acaso conocedora de otros códigos legales más estrictos en casos de forçamiento. En la séptima partida de Alfonso X el Sabio, se repudia tajantemente este acto: "Atrevimiento muy grande facen los homes que se aventuran á forzar las mugeres, mayormente quando son vírgines, ó mugeres de órden ó vibdas que facen buena vida en sus casas ó de sus padres» (título XX). Quien incurriere en tal "yerro et maldat» «debe morir por ello» y sus bienes pasan a ser parte de la mujer forzada. Y «esa misma pena deben haber los que ayudaren á sabiendas á robarla ó á forzarla». Empero, si la mujer decidiere casarse con el hombre que la forzó, los bienes pasarían a ser parte de los padres de la deshonrada, si es que no consintieron ni el forzamiento ni el matrimonio, pues si se probare que los hubieron consentido, entonces los bienes pasarían a ser propiedad del rey. Dicho esto, no nos debe sorprender que ambas mediadoras recurran al matrimonio como solución a la falta, a fin de evitar que el asunto llegara a mayores. Salta a la vista que estas consideraciones, al igual que el disgusto de la dama en el acto, son originales del autor anónimo y no forman parte de la tradición erotológica que hemos venido explorando y que seguiría teniendo larga vida en Europa. Tal amplificatio, aunque ficcional, parece manifestar las consecuencias de la puesta en práctica de fórmulas librescas en la vida real. Otro tanto harían los autores de la Tragicomedia. 
Aunque una golondrina no hace verano, puede llegar a resultar conmovedor cómo el manual, al mismo tiempo que ilustra el proceso de amores con todo lujo de detalles, revela la falta de aquiescencia de la mujer ante la total falta de refinamiento sexual de su enamorado y la total ausencia de placer. Tan cerca de Ovidio y a la vez tan lejos. Pero en lo que toca a la exposición, el autor anónimo sigue de modo intachable las enseñanzas heredadas ${ }^{52}$, las mismas que también heredarían don Melón de la Huerta y Calisto. Y no es poco elocuente el enorme éxito que alcanzó este librillo erótico en la Europa medieval. Traducido a las lenguas más diversas, incluyendo el nórdico antiguo, refundido por muchos, recitado por juglares, también formó parte de los programas escolares ${ }^{53}$. La dilatada proliferación de este manual en toda Europa prueba cuán extendido estuvo este ars amandi en los siglos medios. Pánfilo pasó a formar parte de la lista de los autores más admirados de la época, según lo registra fray Migir en el Cancionero de Baena:

$$
\begin{aligned}
& \text { Boeçio, Panfilo, Oraçio e Nasón, } \\
& \text { Tulio, Vegeçio, Virgilio e Catón. } \\
& \text { (apud Rubio y González Rolán 1977, p. 26) }
\end{aligned}
$$

Es, además, uno de los libros recomendados por don Amor al arcipreste de Hita para aprender «muchas buenas maneras para enamorado» (estrofa 429). «Buenas maneras» que reiteran unos modos rudos y violentos que llegarían hasta Calisto.

De estas «maneras» se sirve el enamorado del Roman de la Rose para alcanzar la rosa por la que muere. Su Amigo, ante la aflicción en que se encuentra el penado amante, lo alecciona en el arte de seducción — basado, por supuesto, en el fingimiento-y detalla el proceder último de modo similar a las exposiciones anteriores:

Habréis de tomar la rosa aunque Rechazo os injurie, o
Vergüenza y Miedo gruñan, si observáis que lo hacen por
fingir o por defenderse sin fuerza para confesarse venci-
dos. Aunque veáis a Miedo temblar, a Vergüenza sonro-
jarse y a Rechazo estremecerse, o a los tres juntos llorary

52.- El empleo de la violencia en el acto formaba parte de las instrucciones de Venus: «Si locus est, illi iocundis uiribus insta / (...) / Pulchrius esse puta tui perdere uirginitatem / Quam dicat: "De me fac modo uelle tuum»» (vv. 109-114). También la Anus espolea a Pánfilo para que muestre su hombría en cuanto sea oportuno con su «te precor esse uirum» (v. 546). Los mismos consejos aparecen calcados, y aun ampliados, en la refundición de Juan Ruiz.

53.- Lisardo Rubio y Tomás González Rolán resumen así su éxito: «Los estudiantes copian, leen, traducen, comentan y recitan los 780 versos de la obra. Algunos llegan a dominar la materia con tal «maestría» que se atreven a ampliar ocasionalmente el texto; el caso más notable - aunque no el único, ni mucho menos- de estas interpolaciones se halla en la escena de la violación (681 y sgtes.), escena demasiado escueta para el gusto de cierto sector estudiantil en los ejemplares ad usum» (1977, pp. 29-30). 
gemir, no os importe una higa: tomad la rosa por la fuerza y mostrad que sois hombre en cuanto lleguen el lugar, el momento y la estación. Nada les gusta más que esa fuerza en quien sabe ejercerla. Muchas personas tienen tan extraños hábitos, en efecto, que sólo ceden ante la fuerza lo que de grado no se atreven a dar, y fingen perderlo cuando en el fondo lo desean y quieren. Así, sabed que quedarían dolientes si su resistencia venciese; aunque fingieran gozo, no dudo que os odiarían, sintiéndose irritados, a pesar de sus protestas. (Lorris y Meun 2003, p. 159)

El sumario es el mismo: todas las fenbras, al comienzo del fecho, se muestran reacias, enfadadas y amenazantes, pues «el miedo e la vergüença faze a las mugeres / non fazer lo que quieren». "Por mejor tiene la dueña de ser un poco forçada". "Ruégovos que seades omne do fuer lugar» (estrofa 823). «Te precor esse uirum». A ella le place esa fuerza, pues, si por su resistir el varón renunciase a seguir adelante, ella terminaría triste y decepcionada. Pues quien posterga el uso de la fuerza, «rusticus est, nunquam dignus amore magis». ${ }^{54}$

Estamos, pues, ante un código amatorio ampliamente difundido en la Europa medieval ${ }^{55}$. Tan codificado que no falta la ocasión en que la dama se ve obligada a descodificarlo a su enamorado, que se lamenta

54.- Jean de Meun, sin embargo, al igual que Ovidio, no escatima en detalles al describir el placer, ese bien que concede Natura, y propone como ideal la consecución del orgasmo mutuo: "Y cuando estén en plena obra, cada uno actuará con tal juicio y sentido que el placer de uno y otro llegue sin falta en común y en el mismo instante, antes de concluir el acto. Deben esperarse el uno al otro para alcanzar juntos el final. Uno no debe dejar al otro atrás. No deben dejar de navegar hasta llegar juntos a buen puerto. Sólo entonces gozarán del más intenso placer» (2003, p. 249). Pero: "Y si ella no encuentra placer en esto, habrá de fingirlo. Que imite y muestre todas las señales que conoce como placenteras, de modo que él crea que le agrada lo que en realidad aprecia menos que una castaña».

55.- Para no agobiar al lector con tantas citas, me limito a ofrecer al pie de página solo dos ejemplos más de este código en la literatura francesa. El primero proviene de la Clef d'amors, un arte de amar ovidiano del siglo XIII:

James fame n'oseroit dire de bouche cen que tant desire; mes mont li plest que nen la prenge mal gre soen, comment qu'il avienge.

Pucele soudement ravie

a grant joie, que qu'ele die. (vv. 1141-1146)

En español, leería más o menos así: «Nunca una dama osaría a decir con su propia boca lo que tanto desea; más bien, le agrada bastante cuando alguien la toma contra su voluntad, sin importar cómo. La doncella súbitamente forzada siente gran alegría, no importa lo que diga». El segundo ejemplo es de Perceval ou le Conte du Graal, de Chrétien de Troyes, que en traducción de Martín de Riquer leería así: «La mujer que entrega su boca, muy ligeramente da todo lo demás [le soreplus], si hay quien bien lo entienda. Y aunque ella se defienda, ya se sabe, sin duda alguna, que la mujer siempre quiere vencer, excepto únicamente en aquella pelea en la que tiene el hombre cogido por la garganta, y araña, muerde, forcejea, pues entonces quisiera 
por la excesiva pudibundez de ella y se ve obligado a forzarla. Así en el Cancionero de Ripoll:

Simplicis ingenii nimis es, non insipientis:

Virgineę nescis que sit meditatio mentis.

Cum prohibet tactum, uult ne meretrix uideatur;

Condolet interius, nisi, quod negat, illud agatur ${ }^{56}$.

Pero no quedaron nada lejanos estos mores eróticos de la España de Rojas. Muy cerca están las «bodas sordas» del Tirant lo Blanc, que tan bien Rafael Beltrán (1990) ha sabido poner en diálogo con la Tragicomedia. Allí, las «escenas lúbricas» y "cuadros lascivos» de los que hablara Menéndez Pelayo se desarrollan a partir de los consejos amatorios expuestos. Placerdemivida, dando cuenta de lo visto y oído a hurtadillas, atestigua la "gran prisa» (2005; cap. 163 , p. 413) con que Diafebus besaba y desnudaba a la virgen Estefanía. Ella se resistía: "¡Ay, señor, que me hacéis daño! Compadeceos un poco de mí y no me queráis matar del todo (...) ¿Qué haré, triste de mí? El dolor me obliga a gritar y, por lo que veo, estáis decidido a matarme». Tan decidido estaba que la remata con un tapaboca. Y no será muy distinto lo que viva Carmesina con Tirant, que, si bien no pierde su virginidad esa noche, cuando le llega el momento, a la altura del capítulo 436, ha de resistir la "belicosa fuerza» del caballero enamorado (2005, p. 814). Ella intenta disuadirlo: «no por la fuerza, sino con ingeniosos halagos y dulces engaños se logran [los combates del amor]». Pero no tiene éxito: «¡Ay, Señor! ¿Cómo puede deleitaros una cosa forzada? ¡Ay! ¿Puede permitiros el amor que hagáis daño a la cosa amada? Deteneos, señor, por vuestra virtud y acostumbrada nobleza. (...) Tened piedad (...) ¿Eso es lo que yo tanto deseaba? ¡Oh esperanza de mi vida, aquí tienes a tu princesa muerta!». Es plausible imaginar que la enamorada no supiera lo que implicaban sus deseos. Pero, con todo, tras despertar de su amortecimiento, retoma su gozo: «Los dos amantes pasaron toda la noche jugando a aquel venturoso deporte que suelen practicar los enamorados» (2005; cap. 437, p. 815). Tirante comenta en el capítulo 439: «Aprecio tanto haberlo obtenido con violencia como si por libre voluntad me fuese otorgado» $(2005, \text { p. } 817)^{57}$.

ser la vencida. Se defiende, y es tan cobarde en su entrega, que está impaciente y quiere que se le haga fuerza» (1992, pp. 110-111).

56.- «Eres de natural muy ingenuo, aunque no un inconsciente: no sabes cómo piensa de una doncella la mente. Cuando el contacto rehúye, no quiere parecer una mujerzuela; mas por dentro se duele si lo que rehúsa no se hiciera». He citado por la edición bilingüe de los Carmina Rivipullensia realizada por José-Luis Moralejo (1986, p. 227).

57.- Resulta interesante la opinión de Beltrán: «Rojas se compadece de Melibea, mientras que Martorell se mofa despiadadamente de Carmesina, poniendo en boca suya un discurso ridículo» (1990, p. 106). Con respecto a esta batalla de amor, véase el lúcido ensayo de Manuel Lara Cantizani (1997). 
Alfonso Martínez de Toledo denuncia implacablemente en el Arcipreste de Talavera o Corbacho (1438) la hipocresía de la mujer que «disimula non amar, non querer e non aver» (2011, pp. 199-200), que se hace la fría, pero que arde por dentro, $y$

encúbrelo, porque si lo demostrase, luego piensa que sería poco presçiada; e por tanto quiere rogar e ser rogada en todas las cosas, dando a entender que forçada lo faze, que non ha voluntad, diziendo: «үuyy, dexadme! ¡Non quiero! ¡Yuy, qué porfiado! (...) ¡Estad en ora buena! ¡Dexadme agora estar! ¡Estad un poco quedo! ¡Ya, por Dios, non seades enojo! ¡Ay, paso, señor, que sodes descortés! ¡Aved ora vergueña! ¿Estáis en vuestro seso? (...) ¡Líbreme Dios deste demoño! ¡Y andad allá si quieres! ¡O cómo sois pesado! ¡Mucho sois enojoso! ¡Ay de mí! ¡Guay de mí! ¡Avad, que me quebráis el dedo! ¡Avad, que me apretáis la mano! ¡El diablo lo troxo aquí! ¡O mesquina! ¡O desventurada! ¡Qué noramala nasçí! ¡Mal punto vine aquí! (...) ¿Y piensa que tengo su fuerça? ¡Todos los huesos me a quebrado! ¡Todas las manos me a molidas! (...) ¡O triste de mí! ¿Quién me engañó? ¡Maldita sea la que jamás en ombre se fía, amén!» Esto e otras cosas dizen por se honestar, mas Dios sabe la fuerça que ponen nin la femençia que dan a fuir nin resistir; que dan bozes e están quedas; menean los braços, pero el cuerpo está quedo; gimen e non se mueven; fazen como que ponen toda su fuerça mostrando aver dolor e aver enojo. (2011, p. 200)

Tales modos eróticos pervivirían aun en el Siglo de Oro español, según evidencia el siguiente soneto erótico anónimo (aparece en dos códices, atribuido el uno a un tal Brahojos y el otro a Quevedo):

—QQué hacéis, hermosa? -Mírome a este espejo.

- ¿Por qué desnuda? - Por mejor mirarme.

- ¿Qué veis en vos? - Que quiero acá gozarme.

-Pues, ¿por qué no os gozáis? —No hallo aparejo.

— ¿Qué os falta? - Uno que sea en amor viejo.

—Pues, ¿qué sabrá ése hacer? — Sabrá forzarme.

- ¿Y cómo os forzará? - Con abrazarme, sin esperar licencia ni consejo.

- ¿Y no os resistiréis? - Muy poca cosa.

- ¿Y qué tanto? - Menos que aquí lo digo, que él me sabrá vencer si es avisado.

${ }_{-}$¿Y si os deja por veros regurosa? 
-Tenerle he yo a este tal por enemigo, vil, necio, flojo, lacio y apocado. (Alzieu et al. 2000, p. 30)

Imaginamos que ese "en amor viejo" no es sino un experto en las enseñanzas ovidianas. No faltan consejos similares dirigidos a las damas casadas a fin de hacerse desear por sus maridos y así evitar el desinterés erótico que acompaña el matrimonio:

Siempre habéis de mostrar que sois forzadas, que os vence el marido, y con reparos de resistencia siempre habéis de armaros, y veréis cómo sois más estimadas. (Alzieu et al. 2000, p. 30)

Recomiendan estos erotólogos huir del almibarado agere de los casados, en que, por zanjar el débito conyugal, los maridos saltan los prolegómenos ad excitandum feminam y las casadas, prestas a cumplir su parte, olvidan «aquel su resistir (...) y aquel pidiros que miréis su fama» (Alzieu et al. 2000, p. 25) típico de la doncella, llegando ambos a un pronto fin sin haber superado obstáculos que aviven su deseo. Pues en tal contienda queda cifrado lo mejor del deleite:

Aquel llegar de presto y abrazalla, aquel ponerse a fuerzas él y ella, aquel cruzar sus piernas con las della, y aquel poder él más y derriballa; aquel caer debajo y él sobre ella, y ella cobrirse y él arregazalla, aquel tomar la lanza y embocalla, y aquel porfiar dél hasta metella; aquel jugar de lomos y caderas, y las palabras blandas y amorosas que se dicen los dos, apresurados; aquel volver y andar de mil maneras, $y$ hacer en este paso otras mil cosas pierden con sus mujeres los casados. (Alzieu et al. 2000, p. 35-36)

Nada más estimable que «el pedir dél y negar ella, / y aquel ponerse a fuerzas él y ella» (p. 37), que "aquel meterse dentro y salir fuera / hasta que la camisa hace pedazos», etcétera ${ }^{58}$.

58.- Remito al lector a la elocuente glosa del soneto citado en Alzieu et al. (2000, pp. 3541). Para este bienhumorado ars amandi expuesto en el Jardín de Venus, «enunciado por una voz masculina (en el papel de praeceptor amoris ovidiano) y destinado a la educación erótica (burlesca, si se quiere) de la mujer", remito al artículo de Javier Blasco (2015; cita en p. 162). Vale insistir: los consejos, aunque en van dirigidos a las damas, tienen por fin agradar a los maridos para evitar sus posibles infidelidades: «Si la dama un poquito se esquivase / cuando quiere gozarla su marido, / haría, con tenerlo un poco en pena, / que con mayor deleite la gozase, / y por ella anduviese tan perdido / que nunca se acordase de la ajena (Alzieu et al. 2000, p. 26). 
Ha quedado establecido, pues, el arte de amar más divulgado en el Occidente medieval, ese que tan finamente supo poetizar el clérigo vagante con que iniciábamos este apartado. No nos queda duda de que la historia de los amantes Calisto y Melibea pertenece a esta consabida tradición. Si no nos quedaba demasiado claro el proceder de Calisto en el primer encuentro, cuando las «impúdicas manos» osaron a llegar a las "parte più segrete» "en tan poco espacio» de tiempo, el segundo encuentro, a la altura de un mes de relación, nos revela la conducta venérea de Calisto y, de paso, la inconformidad de su enamorada. Leídos los reclamos de Melibea a la luz de esta tradición, comprendemos por qué le fue tan enojoso el «riguroso trato» recibido. Y nos permite comprender aquella inusitada demanda: "Holguemos y burlemos de otros mil modos que yo te mostraré; no me destroces ni maltrates como sueles. ¿Qué provecho te trae dañar mis vestiduras?» (XIX, p. 321). No cabe duda de que Calisto es de aquellos que disfrutan "aquel meterse dentro y salir fuera / hasta que la camisa hace pedazos». Para el joven, los remilgos de Melibea no son otra cosa que la resistencia fingida que forma parte del juego erótico:

Pero tú, dulce imaginación, tú que puedes, me acorre. Trae a mi fantasía la presencia angélica de aquella imagen luciente; vuelve a mis oídos el suave son de sus palabras, aquellos desvíos sin gana, aquel «Apártate allá, señor, no llegues a mí», aquel «No seas descortés» que con sus rubicundos labrios vía sonar, aquel «No quieras mi perdición» que de rato en rato proponía; aquellos amorosos abrazos entre palabra y palabra; aquel soltarme y prenderme; aquel huir y llegarse; aquellos azucarados besos; aquella final salutación con que se me despidió... (XIV, pp. 282-283)

Así ve Calisto su encuentro erótico con Melibea. Y puede que así hubiera sido.

Pero la osada propuesta de Melibea también podría delatar, por otra parte, su inconformidad ante unos modi que se suceden demasiado raudos - modos que, como acabamos de ver, contaban con el beneplácito del personaje femenino-y que descubren la sexualidad incontrolada de Calisto, afín a la de todos los penados amantes de su tiempo ${ }^{59}$. Podría

Los métodos «violentos» expuestos aparecen también, aunque con menos detalles, en obras de Lope de Vega y de María de Zayas, entre otros autores del Siglo de Oro.

59.- Coincido con Eukene Lacarra Lanz cuando señala que Melibea se resiste ante la prisa de Calisto por «rematar la faena» (2000, p. 137), de modo que su queja «No quieras perderme por tan breve deleite y en tan poco espacio» no implica tanto un eco de la expresión tópica entre moralistas (referida por la cortedad del placer sexual frente a las consecuencias del grave pecado en que se ha incurrido), sino como una queja genuina de la rapidez de consumación llevada a cabo por Calisto (2000, p. 138). Ya Lucrecio en el libro cuarto del De rerum natura 
delatar, además, un deseo de experimentar otros mille modi Veneris, ajenos a esta tradición ovidiana medieval, que tanto se ocupó de silenciar la creatividad erótica de la que hiciera gala Ovidio en su manual de amore. ¿Y cómo podrían explicarse estos mille modi que Melibea desea mostrarle a su amante en pleno factum y que parecen proclamarla toda una experta en el arte de amar? De seguro serían unos modos más delicados que la flagrante rudeza de Calisto. Conviene que revisemos muy brevemente algunos textos literarios que constituyen contadas excepciones en cuanto a los procedimientos eróticos se refiere.

\section{Excepciones literarias al ars amatoria predominante en Europa}

El enamorado de Ripoll no solo vislumbró el empleo de la fuerza cuando se vio en los lechos de Venus junto a su enamorada. También supo experimentar "hoscula mille modis» (1986, passim) envuelto en un dulce abrazo inacabable. Y, en otra ocasión, ostenta su amplio conocimiento en lides eróticas al aleccionar a los jóvenes sobre los modos a emplear cuando por fin conozcan el amor:

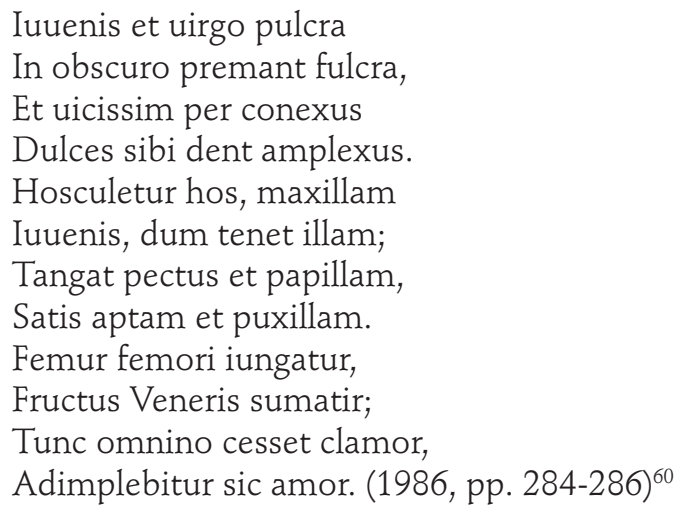

Contamos con otro corpus textual que constituye una excepción a las preceptivas hasta aquí exploradas: las jarchas y la lírica popular. Es cierto que no hallamos allí ninguna exposición formal sobre los modos venéreos, pero sí hallamos voces femeninas que asumieron un rol muy activo en la sexualidad y que podrían guardar cierta afinidad —al menos psicológica - con nuestra protagonista. Las jarchas, esas «encantadoras cancioncillas de amor puestas en boca de muchacha», al decir de Margit

contrastaba los modos violentos e instintivos del varón enfermo de amores y los modos más sensuales y delicados de la mujer. Véase al respecto Robert Brown (1987, p. 66).

60.- «El muchacho y la moza bella en la oscuridad pesen sobre el lecho, y asiéndose mutuamente dulces abrazos se den. Bese su boca y mejilla el joven mientras la tiene; toque su pecho, [el pezón], tan bien formado y pequeño. Únase muslo con muslo, tómese el fruto de Venus; cese luego el griterío, y será el amor cumplido». 
Frenk (2015, p. 15), pueden llegar a ser altamente sensuales, como aquella en que la muchacha, al decir de Peter Dronke, «aguijonea su deseo con la urgencia de una nueva forma de hacer el amor» (1995, p. 110):
Tant t'amaray, illa con al-šarti
an taĝma' halhali ma' qurti!

\author{
¡Tanto te amaré, sólo con que \\ ajuntes mi ajorca del tobillo \\ con mis pendientes! \\ (apud Dronke 1995, p. 111)
}

Comenta con razón Dronke: "Más que una amada es una amante activa» (1995, p. 110).

En el cancionero popular, también hallamos mujeres dispuestas a tomar la iniciativa amorosa. Los desenfadados y libres versos de estas muchachas se muestran como «expresión directa y franca de sus deseos, sus urgencias sexuales» (Frenk 2006, p. 357) y manifiestan «su clarísima conciencia del derecho a vivir libre y plenamente el amor» (Frenk 2006, p. 372). Además, se trata en las más de las veces de voces gozosas que comparten con Melibea el mismo júbilo sensual ${ }^{61}$. Pero, a pesar de estas afinidades, es preciso admitir que esta poesía se distancia de la preceptiva amorosa tradicional que siguen Calisto y Melibea y en cuya tradición se inserta la Tragicomedia.

Hay otros textos que podrían anticipar algo de la súbita desenvoltura de la amada de Calisto. En la ficción sentimental, que tan idealizante y espiritualizante se han empeñado en leer aun hoy tantos críticos, encontramos uno de los primeros orgasmos femeninos de la literatura española. Lo describe Grimalte -en Grimalte y Gradisa de Juan de Flores-, un auténtico voyeur que espía lo que Fiometa y Pánfilo hacen en «su secreta cámara, retraídos de los suyos»:

Y ellos así retraídos, ¿quién podría dizir las graciosas maneras que en este rescebimiento pasaron? Las cuales, aunque el juizio las siente, mi mano espresar no sabe, en especial, porque el caso consiste más en auctos que en palabras. Pero algo de lo visto no puedo callar, que no creo jamás dos enamorados mejor averse ni con más lindos modos entenderse. Sin duda, cuanto más los yo mirava, tanto de mayores gracias en mis ojos eran representados, porque parescía que el mesmo Dios de los amores los enseñava, para los cuales cient mil secretos tiene reservados. ¡ $\mathrm{O}$ cuán atento yo los mirava, pensando que de sus gracias alguna deprendiese! Pero sus desenbolturas eran dificultosas de hurtar. Yo, a lo menos, contento me hazía en mirarlos, que tanto vencido estava

61.- Remito a las compilaciones de Frenk (2003 y 2015) y a su valiosa colección de estu$\operatorname{dios}(2006)$. 
en dulçor de sus amores, trayendo a memoria los míos, que los amores dellos me davan sentible pena, tales eran sus gentilezas que no sabía cuál de aquellas más loasse. Cada uno procurava por más agradar al otro, que como en sueños me parescía que viese los auctos tan estimados de aquellos dos amadores, (...) ambos en uno de tal manera combatieron, que sobrado gozo la derribó cuasi muerta en el suelo. (2008, pp. 142-143)

Sorprende encontrar en la literatura medieval hispánica unos «lindos modos» como estos que tanto embelesan y aleccionan a Grimalte, y que tanto "gozo" producen a Fiometa. Esta es una de las mayores excepciones literarias, afín, sin duda, a la singularidad erótica de Melibea ${ }^{62}$.

Obras altamente eróticas llegaron a ser los libros de caballerías, tanto que muchos moralistas los condenaron implacablemente como libros de Satanás ${ }^{63}$. Es fácil hallar en ellos doncellas seductoras capaces de tomar la iniciativa erótica ${ }^{64}$. No solo abunda la doncella atrevida que, frecuentemente en la tradición caballeresca francesa, se introduce en el lecho del caballero para conseguir su deleite, sino que personajes de importancia central, como la Oriana del Amadís, son quienes dan el paso hacia la consumación amorosa ${ }^{65}$. Con todo, es preciso señalar que tal iniciativa erótica no se da, en el fondo, por motivos puramente sensuales, es decir, por el puro goce del amor, sino que forma parte del rol heroico femenino, o, en el caso de los personajes femeninos menores, para acentuar el heroísmo del caballero. Ello no impide que haya ciertas concomitancias entre Melibea y alguno de estos personajes, como la Oriana del Amadís primitivo. Bienvenido Morros ha puesto en manifiesto el paralelismo entre esta "Oriana sensual, desenvuelta, apasionada y atrevida", "atormentada por las mismas necesidades sexuales que su amado" y arisca al matrimonio (2005, pp. 195, 213, 215 y 218), y nuestra protagonista.

Con todo, a pesar de las frecuentes condenas por lascivia, no es mucho lo que podemos saber sobre los modi Veneris empleados por los personajes de estas obras caballerescas, pues el factum, las más de las veces, es pasado en silencio. Algunos moralistas, como fray Juan Pineda, hubieron

62.- Otro orgasmo femenino en la literatura hispánica es el descrito en el mamotreto XIV de La Lozana andaluza de Francisco Delicado (entre 1528 y 1530). Lozana, por cierto, se queja de la prisa de Rampín: "Pasico, bonico, quedico, non me ahinquéis. Andá conmigo, jpor ahí van allá! ¡Ay, qué priesa os dais (...)! Catá que no soy de aquellas que se quedan atrás. Esperá (...) Y mira que por muncho madrugar, no amanece más aína. (...). ¡Aquí va la honra! (...) ¡Ay, amores, que soy vuestra, muerta y viva! (...) ¡Allí, allí me hormiguea!» (2013, pp. 62-65).

63.- Véanse los abundantes ejemplos recogidos en Glaser (1966).

64.- Véase María del Rosario Aguilar Perdomo (2004).

65.- Así en el Amadís: «se puede dezir que en aquella verde yerva, encima de aquel manto, más por la gracia y comedimiento de Oriana, que por la desemboltura ni osadía de Amadís, fue hecha dueña la más hermosa donzella del mundo» (2012, p. 574). 
de admitirlo: «Muy peor la lección de Celestina que la de los libros de caballerías, en que no ay la práctica carnal, y ai otras virtudes muy platicadas, como la de la honrra, verdad, amistad, crianza y generosidad» (apud Glaser 1966, p. 402). Así pues, estas "diabólicas lecturas de amor», al decir de fray Juan de la Cerda (apud Graser 1966, p. 406), se quedan parcas en detalles en comparación con nuestra obra en cuestión. Aunque un ejemplo sí que podríamos aducir sobre el proceder último en los tálamos de Venus, pero no ya de los libros de caballerías hispánicos, sino de El caballero de la Carreta de Chrétien de Troyes. Advertimos no el proceder violento que el escritor francés expusiera en su Perceval (vid. supra, nota 55), sino una gran delicadeza y morosidad que acabaría por inspirar numerosas refundiciones en la Europa medieval:

Ante ella se postra, y la adora: en ningún cuerpo santo creyó tanto como en el cuerpo de su amada. La reina le encuentra en seguida con sus brazos, le besa, le estrecha fuertemente contra su corazón y le atrae a su lecho, junto a ella. Allí le dispensa la más hermosa de las acogidas, nunca hubo otra igual, que Amor y su corazón la inspiran. De Amor procede tan cálido recibimiento. (...) Ahora ve cumplido Lanzarote cuanto deseaba, pues que a la reina le son gratas su compañía y sus caricias, y la tiene entre sus brazos y ella a él entre los suyos. Tan tiernos y agradables son sus juegos, tanto han besado y han sentido, que les sobreviene en verdad un prodigio de alegría: nadie oyó hablar jamás de maravilla semejante. Pero nada diré al respecto: mi relato debe guardar silencio. De entre las alegrías, quiere la historia mantener oculta y en secreto la más selecta y deleitable. (2013, pp. 118-119)

Quizá esta sí podría pasar por una de esas «diabólicas lecturas de amor» condenadas por fray Juan de la Cerda, pues fue precisamente la lectura de los amores de Lanzarote y Ginebra lo que condujo directamente al infierno a Francesca de Rímini y a Paolo en la Comedia de Dante.

Acaso Melibea también fuera una ardiente lectora de alguna de estas «diabólicas lecturas», de las cuales prosigue diciendo fray Juan de la Cerda en su exposición: "En media hora hace más daño un libro de amores, o de cosa semejante, a la doncella desadvertida de sus daños, que una ruin tercera en muchas horas de conversación" (apud Aguilar Perdomo 2004, p. 5). Acaso sí hubiera leído en la biblioteca de su padre una obrita que circulaba como best seller en la Europa de su tiempo: la Historia de duobus amantibus de Eneas Silvio Piccolomini. Ya he dicho que la protagonista Lucrecia es el antecedente literario más cercano a Melibea (Matos 2018a). El proceso de amores se desarrolla casi exactamente igual en la obra de Piccolomini y en la de Rojas, con la única excepción de que la protagonis- 
ta de la obra del italiano está casada. Al igual que en la Tragicomedia, hallamos narrados dos encuentros eróticos entre los protagonistas Euríalo y Lucrecia. El primero sucede de modo similar al de Calisto y Melibea: la dama se resiste, pero al final acaba vencida. Sin embargo, en el segundo encuentro nos topamos con una sorpresa: la noche de amor vivida por los dos amantes resulta ser más dulce que cualquiera de las vividas por Venus y Marte. Euríalo explora morosa y delicadamente cada rincón del cuerpo de su amada, alabando cada parte al mismo tiempo que la besa:
¿Qué cosa ay más hermosa que estos miembros? ¿Quál blancura mayor? (...) ¡O pecho hermoso!, o tetillas resplandecientes!, ¿es verdad que os trato, es verdad que os tengo, es verdad que venistes a mis manos? ¡ $\mathrm{O}$, miembros rollizos! ¡O, cuerpo oloroso!, ¿es verdad que te posseo? Agora sería conveniente el morir siendo este placer fresco $(. .). ¡ \mathrm{O}$, besos suaves! $\mathrm{O}$, dulces abraçados! $¡ \mathrm{O}$, bocados llenos de mucha dulzura! Ninguno más bienaventuradamente que yo bive, ninguno mejor afortunado. Mas jay, qué ligeras oras! ¡O, embidiosa noche!, ¿por qué huyes? Está quedo, Sol, en lo baxo mucho tiempo. ¿Por qué tan presto traes los cavallos al yugo? Déxalos por mi amor pacer, no te apressures tanto en mi daño. (2001, pp. 211-212)

Tras las exclamaciones, que se extienden a casi una página, concluye el narrador: "Assí Euríalo, y no menores cosas dezía Lucrecia. Ninguna palabra ni beso passava sin recompensación. Apretava el uno, estreñía el otro. Ni después del juego quedavan lasos o cansados» (2001, p. 212). Las caricias de los dos amantes silencian toda la tradición rauda y violenta que les precede y que con tanta vivacidad intenta rechazar Melibea al proponer a viva voz «mil modos» alternos de hacer el amor ${ }^{66}$.

And yet, and yet... ¿Son suficientes estos ejemplos literarios excepcionales para justificar la pericia erótica de Melibea y su audacia al proponer a su enamorado nuevos modos de hacer el amor? Frente a la rápida consumación que puede ofrecer Calisto, Melibea parece reclamar una morosidad que implica unos mille modi Veneris ajenos a la mayor parte de la tradición erótica medieval y que muy pocas amadoras literarias, como acaso Fiometa, Ginebra y Lucrecia, pudieron experimentar. Ante la novedad de la proposición de la hija de Pleberio, Bienvenido Morros sugiere que la joven pudo haber aprendido tales modos leyendo los manuales teológicos de Tomás de Aquino, en los que se condenan ciertas prácticas lujuriosas consideradas pecaminosas: 
Sorprende que una muchacha que había pasado los veinte años de vida encerrada en su casa bajo la atenta vigilancia de sus padres tuviera esas nociones tan actuales sobre sexología. Podía haberlas adquirido en los manuales de teología que las denuncian como asociadas al pecado de la lujuria. (2009, p. 163)

No se contentaba con la "fornicatio simplex", sino que buscaba nuevas fórmulas de placer, las que los teólogos como santo Tomás en su Summa Theologica habían catalogado como pecado mortal (en la presentación de esa especie de lujuria había sustituido "complexus» por «tactus» y había incluido la coletilla «et aliis huius modi illecebris»: «Et ideo, cum oscula et amplexus et huiusmodi fiant, consequens est quod sint pecata mortalia». (2009, p. 176)

Melibea le propone otras prácticas sexuales con las que espera poder gozar más de lo que ha gozado en el último mes. Puede haberlas leído en los manuales de teología que las denunciaban, sin entrar en demasiados detalles sobre en qué consistían, como motivo de pecado mortal. Es imposible que las haya conocido a través de ciertos libros de sexología que las recomendaban como modo infalible para obtener mayores deleites en las relaciones sexuales. Melibea no descubre nada que no estuviera ya inventado en sexología. (2010, p. 82)

Especular sobre las lecturas de un personaje de ficción podría parecer arriesgado. Sin embargo, a pesar de que tal realidad exceda los límites del texto, evaluar el corpus textual que pudiera haber adoctrinado a Melibea en estos saberes no es un esfuerzo del todo infructuoso. Todo lo contrario: logramos acceder al imaginario de una época que ya nos es ajena y de un personaje que no deja de palpitar vivamente delante de nuestros ojos. La opción ofrecida por Morros, en principio, parece sensata: a fin de cuentas, esos modi, pecaminosos o no, se corresponden con la demanda de Melibea de gozar más, sobre todo de los preliminares del coito. Sin embargo, contamos con un corpus mucho más amplio y aleccionador, más compatible con las libertades eróticas y morales de Melibea que las lúgubres y angustiadas condenas del teólogo, tan opuestas al alborozo vital de la joven. Me refiero a los tratadistas médicos posteriores a Avicena, que, sin ser en sí mismos "libros de sexología», parecen ser más armonizables con las peticiones de Melibea, asaz contradictorias con el «riguroso trato», tan libresco, de Calisto. 


\section{«Delectatio cum gaudio». Sobre la scientia sexualis en la Edad Media}

"Nihil quod sit naturale est turpe, illud est naturale, ergo non turpe est, donum namque creationis est». Así de contundente se expone en las cuestiones salernitanas (c. 1200) la esencia natural del coito, esa comixtión carnal acompañada de una gran delectación (Lawn 1979, p. 9). Como nada que sea natural es deshonesto, indigno o vergonzoso, tampoco lo es para el filósofo natural hablar sobre ello. La idea de que el coito ha sido creado por Dios para perpetuar la especie, tan cónsona con el crescite et multiplicamini bíblico, sirve de salvoconducto a muchos expositores para detallar todo lo relativo a los usus Veneris ${ }^{67}$. Aunque, ese no fue el único móvil de estos tratadistas: además de asegurar la perpetuación de la especie, el coito es, junto con el alimento, la bebida y el sueño, una de las cosas que conservan la buena salud del individuo ${ }^{68}$. Tanto es así que un refundidor o continuador anónimo de la obra de Constantino Africano, en el Liber minor de coitu, advierte sobre los peligros de quienes por amor a la castidad y consagración al estudio se niegan a satisfacer los deseos de su naturaleza («aliquot qui castitatis favore et amore philosophie nature noluerunt obsequi») y caen en un estado próximo a la melancolía (Montero Cartelle 1987, pp. 78-81). Surge, así pues, una suerte de moralis neutralitas, es decir, un olvido de la noción de pecado, que propicia el interés de muchos tratadistas médicos por el amor, ya desculpabilizado, y aun por la delectatio venérea, pues el amor no es otra cosa que «delectatio cum gaudio", queda establecido en las cuestiones salernitanas ${ }^{69}$.

67.- Así inicia su Liber de coitu Constantino Africano: «Creator volens animalium genus firmiter ac stabiliter permanere et non perire, per coitum illud ac per generacionem disposuit renovari, ut renovatum interitum ex toto non haberet. Ideoque complasmavit animalibus naturalia membra que ad hoc opus apta forent et propria, eisque tam mirabilem virtutem et amabilem delectacionem inseruit ut nullum sit animalium quod non pernimium delectetur coitu» (Montero Cartelle 1983, p. 76).

68.- Más abajo en la obra de Constantino: «Dicit enim Galenus in libro artis (...) veraciter utilis est coitus et proficiens ad salutem» (Montero Cartelle 1983, p. 112). Comenta Bernardo de Gordonio en su Lilio de medicina: "E dize Constantino que pocos fazen coitu por causa de la generación, e los más lo fazen por la sanidad, pero los muchos más lo fazen por la delectación» (1991, p. 304).

69.- «Amor nichil aliud sit quam delectatio cum gaudio» (Lawn 1979, p. 10). La falta de espacio me obliga a sucintar en demasía la exposición. El influjo naturalista se debió, en gran medida, a las traducciones médicas del árabe y, debido al conflicto entre tales ideas y los principios morales cristianos, muchos médicos hubieron de ser muy cautos al principio en sus exposiciones, pues no faltaron las condenas de este tipo de ideas heterodoxas. La más famosa es la implacable condena pronunciada por el obispo de París, Étienne Tempier, en 1277 (Roland Hisette 1977). Para algunos datos sobre cómo algunos teóricos manejaron este conflicto, véase Jacquart (2001). Acerca de la angustiada postura asumida por Occidente en torno al erotismo, véanse Brown (1993), Pagels (1988) y López-Baralt (1992). Para un resumen de las distintas voces medievales en torno a la sexualidad, véanse Jacquart y Thomasset (1989) y Baldwin (1994). 
Parecería que oyéramos a Melibea en esa definición "científica» del amor, que tanto privilegia el placer y el gozo. Basta con abrir unos pocos tratados médicos para hallar un apoyo auténtico a las protestas y propuestas de Melibea, tan inconforme con la tradición libresca en la que está inserta.

La scientia sexualis, como bien han explicado Danielle Jacquart y Claude Thomasset (1989, pp. 115-146), pasó a ser una sección importante de los tratados de medicina medievales, la mayoría, cabe decir, de origen oriental. Desde las ya citadas traducciones del árabe realizadas por Constantino Africano hasta los comentarios y refundiciones del Canon de Avicena, se va haciendo posible abordar ciertos problemas relacionados con el placer venéreo. La libertad de palabra que tiene el médico al tratar de un asunto natural, estrechamente ligado con la buena salud del individuo y la perpetuación de la especie, lo autoriza a hablar de amor sin que ello sea cosa lasciva.

Es cierto que el Liber de coitu de Constantino, como advierte MonteroCartelle, no es una obra "de intencionalidad erótica» y aborda "la problemática sexual única y exclusivamente en lo que concierne al hombre» (1983, pp. 32-33 y 24). Se trata aún de una "sexualité medicalisée», por decirlo con la oportuna expresión de Jacquart y Thomasset, como no deja de serlo el Canon aviceniano, que describe con gran libertad los juegos que deben preceder y acompañar el acto, a fin de favorecer la concepción:

Amplius prolongetur ludum et proprie cum mulieribus quarum complexiones non sunt male. Tangat ergo uir eius mamillas cum facilitate et tangat pertinem eius et obuiet ei non permiscendo se ei permixtione uera. Qumque desiderat et affectat, permisceatur ei fricando de ea quod est inter anum eius desuper et uuluam. Ille enim locus est locus delectationis eiuis. Consideret ergo in ea horam in qua fortis fit in ipsa adherentia et incipient oculi eius mutari in rubedinem et eius anhelitus eleuari et uerba eius balbutire. (libro III, fen. 21, tr. I, c. 9) ${ }^{70}$

Cumple aclarar que el galeno postulaba la consecución del orgasmo mutuo debido a la antigua creencia de que la concepción solo se producía si se juntaban las "dos aguas», es decir, el semen masculino y el femenino. Con todo, tales consejos relativos al lusus o praelusio coitus abren una

70.- Traducción castellana incluida en Jacquart y Thomasset (1989, p. 131): «Que los hombres prolonguen el juego con las mujeres cuya complexión no sea mala. Que acaricien sus senos y la región pubiana y enlacen a su pareja sin llegar a la realización plena. Y cuando hayan alcanzado el deseo, se unan a ella frotando la región situada entre el ano y la vulva. Esta es, en efecto, la región del placer. Estén atentos al momento en que se manifiesta una adhesión más vigorosa por parte de la mujer, cuando sus ojos comienzan a enrojecer y su respiración a hacerse más intensa y ella empieza a balbucir». 
puerta en Occidente para el arte erótico, como habremos de constatar en breve. Nos revela, además, información sobre las zonas erógenas femeninas y las señales que ha de seguir el varón para logar excitar a la mujer y alcanzar ambos el mayor placer posible $e^{71}$. Lejos de los jocosos preceptos ovidianos o pseudovidianos, se sugiere una morosidad ajena a la violencia exhibida por Calisto, Pánfilo y toda su estirpe.

Es preciso señalar que los primeros comentadores de Avicena pasaron por alto algunos de estos pasajes, que les parecieron demasiado encendidos, o prefierieron atenuarlos. Tal timidez y autocensura revela la incomodidad occidental de quienes leían como "pornográfico» lo que en realidad era puramente "médico», a la vez que nos permite constatar la plausibilidad de que otros comentadores más atrevidos aprovecharan esta vía abierta para amplificar y privilegiar hasta cierto punto el contenido erótico de sus exposiciones.

Bernardo de Gordonio, en el ya citado Lilio de medicina, obra de amplísima difusión en la Edad Media, repite casi verbatim las enseñanzas de Avicena, aunque añade algunos detalles de interés:

Después de la media noche e ante del día el varón deve despertar a la fembra, fablando, besando, abraçando e tocando las tetas e el pendejo e el peritoneón e todo aquesto se faze por que la muger cobdicie, que las dos simientes concurran juntamente, porque las mugeres más tarde lançan la esperma. E quando la muger comiença a fablar quasi tartamudeando, estonces dévese juntar de todo en todo con el pendejo de la muger en tal manera que el aire non pueda entrar en ellos... (1991, p. 231)

Antes de que el hombre proceda a explorar las zonas erógenas de la mujer con caricias que le aviven su deseo, el médico de Montpellier añade a los preliminares la conversación, los besos y los abrazos, es decir, tres de los cinco gradus amoris que conforman la tradición erótica literaria (alloquium, contactus, oscula), los mismos que asume Melibea a medianoche en el huerto, pese a la descortesía de Calisto, atento únicamente en desplumar su ave. Siempre, es preciso volver a recordar, estos consejos médicos se insertan en el capítulo dedicado a curar la esterilidad, de modo que el objetivo formal es la concepción, aunque el propio Bernardo de Gordo-

71.- Remito al aleccionador ensayo de María Cruz Herrero Ingelmo y Enrique Montero Cartelle (2012), quienes comentan al respecto: «Las revelaciones sobre las zonas erógenas de la mujer, de los mecanismos para excitarla y de los signos recognocibles de la proximidad de la eyaculación se mencionan fríamente, como si de una operación quirúrgica se tratase. En efecto, si se lee con atención el texto, se observa que el hombre no busca su placer abiertamente, sino el de la mujer y, si busca el placer de la mujer, no es por sí mismo, sino para lograr la emisión seminal simultánea oportuna para la concepción. La técnica sexual que se describe es solo un medio para un fin superior, por lo que no parece oportuno hablar de erotismo» (p. 305). Los estudiosos adoptan la expresión de Jacquart y Thomasset de «sexualité medicalisée». 
nio se encargó de comentar pocas páginas antes que los «los muchos más lo fazen [el coito] por la delectación». Sea por la razón que fuere, no nos cabe duda de que Calisto se salta todos los prolegómenos recomendados sobre "la manera como se ha de echar el varón con la muger».

La mayoría de las versiones posteriores del pasaje aviceniano parten, no propiamente del Canon, sino de este pasaje del Lilio de medicina (Herrero Ingelmo y Montero Cartelle, 2012, pp. 308 y ss.). El médico inglés Juan de Gaddesden lo incluye en su Rosa anglica (siglo XIV), aunque no sin añadir algunos detalles de su propia cosecha. En primer lugar, el hombre debe prepararse anímicamente alejando de sí toda tristeza, alegrándose y escuchando canciones eróticas, entre otras cosas: «Viri versentur in gaudio, audiant cantilenas Venereas, \& loquantur de coitu: videant homines coeuntes, \& animalia coeuntia, caveant tristitiam quovis modo» (1595, p. 555). Recordamos las cancioncillas eróticas con las que justamente Melibea y Lucrecia reciben a Calisto en el auto decimonono. La alusión al gozo, omnipresente en la Tragicomedia, nos va situando más en el ámbito de la pura delectatio que en el de sterilitate. El médico no se cohíbe al recordar enseguida que el coito "est coniunctum, \& est vehemens delectatio». Más abajo, refunde el pasaje aviceniano a partir de Bernardo de Gordonio:

Post mediam noctem, vel paulo ante, quam dies advenit, mas excitare foeminam debet, ac solicitare ad coitum, loquendo, osculando, amplectendo, mammillas contrectando, tangendo pectinem \& perinaeum, totamque vulvam accipendo in manus, \& nates percutiendo, hoc fine atque proposito, ut mulier appetat Venerem, \& semina concurrant; quia mulieres ut plurimum tardius emittunt sperma, \& cum mulier incipit loqui balbutiendo, tunc debent se commiscere... $(1595 \text {, p. } 555)^{72}$

El médico inglés siente la necesidad de justificarse con Avicena y el objetivo de concebir («Nec vero turpe est, aut culpandum in Medico...», p. 556), pues su exposición aún no ha terminado. Si la mujer no acaba conforme, es decir, si al finalizar el acto siente que no ha emitido su esperma —esto es, no ha tenido el orgasmo-, ella puede tomar la iniciativa en un segundo intento:

Si virga erigatur tarde post primum coitum, \& secundo velis coire mane, ut forte mulier quae non emisit sperma compleat desiderium suum (quod ex eo scitur, quia ipsa

72.- «Después de la media noche, o poco antes de que llegue el día, el varón debe excitar a la mujer y estimularla al coito hablando, besando, abrazando, acariciando sus senos, tocándole los pelos del pubis y el perineo, poniendo sus manos sobre toda la vulva y golpeando las nalgas con el fin y propósito de que la mujer apetezca el acto sexual y luego concurran las semillas, pues las mujeres emiten su esperma mucho más tarde. Cuando la mujer comience a hablar balbuciendo, entonces deberán copular». 
post coitum applicar se viro, eumque amplectitur, \& osculatur, \& postea manum ex abrupto ponit ad virgam \& testiculos viri, ut videat an sit paratus ad pugnam) tunc consultum est coitum repetere, \& paulo ante super dorsum \& renes iacere; quoniam iste decubitus efficit erectionem virgae... $(1595 \text {, p. } 557)^{73}$

Advertimos que el médico se ha contagiado de algunos términos más literarios que médicos para referirse a la cópula, como la pugna o batalla de amor y, antes, el gozo y los cantos de Venus. El médico continúa ofreciendo consejos por si alguno de los dos, hombre o mujer, no se deleita mucho en el acto, que incluyen besos dulces y apasionados ${ }^{74}$, y una lista de afrodisíacos. Salta a la vista que tales preceptos eróticos promueven una morosidad en el acto totalmente ajena a la tosquedad de Calisto y cónsona, en cambio, con las peticiones y propuestas de Melibea. No quedan lejos, por cierto, los modos con que Euríalo dulcemente acariciaba y loaba las partes de su amada Lucrecia mientras las besaba. A fin de cuentas, el objetivo del preludio es despertar el deseo de la mujer a fin de que ambos sientan el mayor de los deleites. A la luz de estos preceptos, podemos comprender con mayor simpatía la queja de Melibea ante el «riguroso trato» de Calisto. Además, hemos visto que Juan de Gaddesden prevé la iniciativa femenina ${ }^{75}$, de modo que no nos sorprende ya tanto la sugerencia de Melibea: «Holguemos y burlemos de otros mil modos que yo te mostraré».

«Esta erotización del discurso médico en Juan de Gaddesden no es accidental; dado que los textos se alimentan mutuamente, dicha erotización no hará sino acrecentarse» (Jacquart y Thomasset 1989, p. 132-133). Michael Savonarola, ya en el siglo XV, al hablar de esta "coniunctio naturalis» en su Practica maior, insiste en prestar atención a la «ludi prolongatio, ex quo mulier multum incitetur, \& in coitu ipso delectetur vltra naturalem delectationem» ${ }^{76}$ (1559, f. 264r). Sabemos que el objetivo del capítulo es favorecer la concepción, pero el médico italiano se excusa por lo que

73.- Traducción castellana incluida en Jacquart y Thomasset (1989, p. 145, n. 100): «Si después de un primer coito la verga tarda en levantarse y quieres copular una segunda vez por la mañana para que la mujer, que quizá no emitió su esperma, dé satisfacción a su deseo (cosa que se sabe porque tras el coito se arrima al varón, le abraza y le besa y deja caer repentinamente su mano sobre la verga y los testículos del hombre, con la idea de ver si está dispuesto al combate), entonces es oportuno repetir el coito y tumbarse previamente sobre la espalda y los riñones, pues esta posición de decúbito provoca la erección de la verga».

74.- "Quod si vir, aut mulier, non delectetur multum in coitu; sumat vir intra palatum candi saccharum, \& tunc comedendo osculetur mulierem, \& linguam suam ponat ad os, \& aperiat labia sua, \& labia mulieris capiat intra sua...».

75.- Comentan Jacquarty Thomasset: «Este es uno de los raros ejemplos que muestran a la mujer con capacidad para una iniciativa que supone cierta técnica» (1989, p. 132).

76.- «la prolongación del juego, que tanto excita a la mujer, y se deleite en el coito más allá del deleite natural». 
pueda parecer deshonesto: «Non dubitabo scribere que sunt vtilia generationi, \& si non videantur auditui honesta ${ }^{77}(1559$, f. 264v). Volvemos a encontrar la descripción aviceniana, aunque con nuevos detalles:

Debet vir mulierem tangere vt circa mamillas, \& leuiter, \& specialiter capita mamillarum oscula iungere, \& verba prouocantia dicere, \& cum virga vuluae appropinquando, non intromittengo, \& vltimo tangendo, $\&$ aliqualiter fricando locum medium inter vuluam \& anum, \& est locus maxime delectationis, deinde virgam intromittere \& aliqualiter prolongare ludum, vt super hoc expectetur emissio spermatis mulieris, quod oculis eius rubeant, \& anhelitus eleuetur, \& quod cum lingua balbutiet. $(1559, \text { f. } 264 \mathrm{v})^{78}$

El pasaje original adquiere nuevos colores en la pluma del médico y humanista italiano, que ofrece detalles más precisos, como el de acariciar y besar «la cabeza» de los pechos, en un latín que estimula fácilmente la imaginación del lector. Se desprende claramente el llamado a evitar las prisas y a prolongar el placer ("prolongare ludum»).

Los médicos no llegan a más. Aunque, a decir verdad, no es poco. Le demos fe o no a la autenticidad del propósito de tales «remedios para la esterilidad», es decir, para favorecer la concepción, tenemos materia suficiente para justificar las exigencias de Melibea, que, menos convencionales que las de su amante, remiten a unos modos eróticos distintos a los que abundan en la tradición literaria occidental, pero afines a los que contemporáneamente con fines más prácticos y reales exponen los médicos medievales, algunos incluso con gran soltura. Los conocieran directamente los autores de la Tragicomedia o no, que no sería improbable dada la intensa afición de los estudiantes salmantinos por la teorización del amor carnal, son ciertamente compatibles con las técnicas amatorias que Melibea dice estar dispuesta a mostrarle a su Calisto.

Cumple que revisemos un último tratado, esta vez, nacido en tierras ibéricas hacia el siglo Xv. Me refiero al Speculum al foder, un manual erótico en toda regla. El anónimo autor, que suponemos médico, esgrime ab initio una fuente árabe: "Dix Albafumet que con sie cosa que los libres [que] parlen en molt foder són molts atrobats, may yo viu d'ells negun compliment en aytal fet, ans los atrobe desviats e escampats en manera

77.- «No dudaré en escribir lo que sea útil para la generación, aun cuando parezca deshonesto».

78.- «El varón debe tocar a la mujer en la zona de los senos y besar suavemente sus pezones, decirle palabras provocativas, acercando la verga a la vulva pero sin meterla, tocando y rozando la región situada entre la vulva y el ano, que es el lugar de mayor placer. Luego debe introducir la verga y prolongar el juego, esperando la emisión del esperma femenino, cuando sus ojos enrojecen, se eleva su respiración y empieza a balbucir». 
que ere major lo dan que havian que lo profit» (1990, p. 45) ${ }^{79}$. Bromas o veras, el autor señala la abundancia de ciertos libros de «foder» en la Península y justifica su contribución por la insatisfacción que le produce el repertorio disponible. Quizás se refiera a los mismos que fascinaran a un cierto deán de Cádiz mencionado en una cantiga de «mal dizer», aficionado a la lectura de libros sobre el «arte do foder» mujeres «mouras». La palabra "arte» remite a un saber "científico», de modo que, como sugiere Francisco Márquez Villanueva (1983), podría tratarse de tratados eróticos de procedencia oriental. Para darnos una idea «acerca de qué y cómo eran aquellos libros del Deán de Cádiz», Márquez Villanueva ofrece como ejemplo el siguiente pasaje de La doncella Teodor:

Otrosi el hombre que asi con ella quiere dormir ha menester que sea sabio e sotil e ingenioso quando dormiere con ella. E el sabio preguntó: «Dime, doncella, en que manera». E ella dixo: «Señor maestro, sabed que si la mujer fuere tardia en su voluntad, deue el hombre que dormiere con ella ser sabio, como dicho tengo, e conocer su complexion; e déuese detardar con ella, burlándose con ella e haziéndole de las tetas e apretándogelas, e a vezes ponerle la mano en el papagayo, e otras vezes tenerla encima de si e a vezes de baxo. E haga por tal manera que las voluntades de los dos vengan a un tiempo. E si por ventura la mujer veniere a complir su voluntad mas ayna que el hombre, deue el con discrecion entenderla e jugar otro rato con ella, porque la haga complir otra vez, e vengan juntas las voluntades de amos, como de suso dixe. E haziéndolo desta manera, amarle ha mucho la muger». (apud Haro 1993, p. 123)

Son los mismos consejos que ofrecían en latín médico los comentadores de Avicena, que fueron un lugar común en la erotología oriental, pero despojados del propósito que solía guiar a los médicos ${ }^{80}$. Y además: ¡en

79.- «Dijo Albafumet que los libros que hablan de joder son muy abundantes, pero yo nunca hallo ninguno que me satisfaga, sino que los encuentro desviados y dispersos, de manera que hacían más daño que provecho» (2000, p. 15). Las citas del original provienen de la edición de Michael Solomon (1990), mientras que las castellanas provienen de la traducción de Teresa Vicens (2000).

80.- Los consejos médicos que hemos revisado, tan ajenos a la tradición literaria europea, son lugares comunes en la tradición oriental. A modo de ejemplo, considérese el siguiente pasaje de un morisco exilado del siglo xvII, autor del ms. S-2: "Antes del acto: es el jugar con ella con todas las çircunstançias de gusto que pueda, besando, abraçando y tentando, para que con esto se contenten y se apresten sus coraçones y pretenciones, de suerte que, alterados y ençendidos en gusto, ella pida a su marido la obra y él la execute con fuerça. (...) Al tiempo de querer meter el miembro, Refregallo en los labios del baso [vagina], porque se altere más él y ella (...). Y estando dentro (...): a de aber otras tres \{maneras\}. La primera: haçer de manera 
boca de una mujer! Una auténtica marisabidilla del amor, como Melibea, propone sus "mil modos» para satisfacer a la mujer, no ya con el fin de concebir, sino por el puro gozo: «E haziéndolo desta manera, amarle ha mucho la muger». Es el único ejemplo en romance del que tengo noticia en que sea una mujer la que hable -y aun aleccione al varón- sobre cómo hacer el amor a fin de incrementar su deleite.

Volvamos al Speculum. El tratado, al igual que en el mundo árabe, no solo está dirigido a médicos, sino que pretende alcanzar un público más amplio, que, según Jacquart y Thomasset (1989, p. 136), podría incluir el sector femenino. El anónimo autor explica con lujo de detalles todo lo relacionado con la ejecución adecuada del acto sexual, si bien tal materia -que incluye los preliminares del enamoramiento (en clave ovidiana, por cierto), el juego erótico y las posiciones recomendadas para el acto- no figura en el índice inicial de la obra, lo que, según Teresa Vicens, podría tratarse de «una treta del traductor (?) para hacer pasar como un simple libro de medicina, donde se cita a Hipócrates y Galeno, un tratado de consejos a los hombres para disfrutar en las relaciones sexuales con las mujeres, sin olvidar de que también éstas queden satisfechas» (2000, p. 10). A fin de cuentas, mucho puede caber en esa "sexualité medicalisée». El autor, que disimula su tratado erótico entre páginas médicas, se aleja por completo del enfoque en la finalidad reproductora y va mucho más lejos que los médicos previos: no solo ofrece métodos para provocar placer, sino también para incrementarlo. Nunca había sido más adecuada la definición propuesta en las cuestiones salernitanas para el amor: "delectatio cum gaudio", que Juan de Gaddesden transformara en «vehemens delectatio». Nada más cercano a Melibea, cuya esencia misma es el gozo por el gozo.

En la última parte del tratado, el autor desarrolla un arte de amar práctico repleto de motivos literarios que se corresponden con el proceso de amores de Calisto y Melibea y otros tantos amantes medievales, incluyendo, por ejemplo, la intervención de la alcahueta y la advertencia a la dama de la muerte que amenaza al penado amante si ella no lo remedia a tiempo. Y procede a explanar con gran detalle todo lo relativo al juego erótico, incluyendo innumerables técnicas para estimular sexualmente a la pareja y para asegurarse de que ambas partes terminen satisfechas por igual, llegando a sugerir hasta veinticuatro posiciones para el acto amoroso. El erotólogo catalán presta especial atención al placer mutuo y aconseja al varón varias técnicas para despertar la libido de la mujer:

Item, les fembres que han atart la volentat del foder, se deuen fer axí: prin la fembra e esten-la e posa-li los jonells

que sea con blandura; no con fuerça, de suerte que no le dé gusto [es decir, que no eyacule prematuramente], y con amor exerçitarlo dentro. La sigunda \{manera\}: que se detenga él lo más que pueda en deRamar [eyacular], hasta que lo hagan los dos a un tiempo, porque proçede desto quererse mucho» (apud López-Baralt 1992, pp. 368-369; énfasis mío). Véase la exposición de López-Baralt al respecto (1992, pp. 309-323). 
al cap de les cuxes; e tinga-li ab la una de les sues mans abdues, e ab l'altre estrenga-li lo cony bé, e la torça, e la pecich entró que crit, es sacuda, es bé plagua; e ab açò, la encendrà que haurà desig de foder, car per açò se scalfarà e mourà sa volentat e lo desig del usar ab homa...

Item, la muller que li ve la volentat atart, e no ha talent de foder, que li façe l'om cinc coses: el besar, el palpar, [el pessigar], el estrèyer, el farir ab les mans... (1990, pp. 80-81) $)^{81}$

En lugar de procurar la consecución del orgasmo simultáneo para propiciar la concepción, el erotólogo la aconseja solo por placer: «realmente no es agradable si los dos placeres no vienen a la vez» (2000, p. 56). Pues: "Cuando el hombre acaba pronto y la mujer tarde, ésta queda muy defraudada", por lo que el hombre deberá jugar con ella hasta que "se caliente y sienta el deseo» (2000, p. 57). Entre los ioci Veneris, sugiere abrazos, besos, caricias, cantos, pellizcos, gestos, miradas, palabras, sonrisas, mostrarse alegre, etcétera. Salta a la vista que no estamos ya ante la fría disquisición de Avicena ni ante un remedium sterilitatis, sino ante un auténtico tratado de amore ${ }^{82}$. Eso sí, un arte de amar opuesto a las refundiciones medievales de Ovidio con que abríamos este capítulo y en las antípodas del tosco desplumar de Calisto y de su rauda rudeza, tan emuladora de Pánfilo y de algunos protagonistas de los festivos cantos goliardescos. A estas alturas, tras haber explorado otros mille modi Veneris contemporáneos a la Tragicomedia de Calisto y Melibea, podemos comprender con mayor simpatía el rechazo de Melibea a la falta de refinamiento y delicadeza de su amado en los tálamos de Venus.

\section{Conclusiones}

Calisto y Melibea intentan seguir, en la medida de lo posible, las convenciones cortesanas sobre el amor, desde el galanteo hasta el goce de la plenitud erótica. Los autores, sin embargo, sabían de antemano que tales convenciones, por más que se adornasen de grandilocuentes parlamentos y se fundamentasen en el disimulo, no hacían sino encubrir un encendido

81.- «Con las mujeres a las que tarda en venirles el deseo debe hacerse lo siguiente: cógela, extiéndela y ponle de rodillas a la altura de la ingle; con una mano tómale las suyas, mientras que con a otra apriétale el coño, retuércela y pellízcala hasta que grite, se rebele o se queje. Así le encenderás el deseo de joder, pues de este modo se calienta y le viene el deseo de yacer con el hombre. (...) A la mujer que el deseo y el orgasmo le tardan en llegar, que el hombre le haga cinco cosas: besarla, sobarla, pellizcarla, estrecharla y herirla con las manos. (...) Debe besarla en la boca, las mejillas, los pechos, las piernas y el vientre. La sobará en la punta de la nariz, las mejillas, los pechos, las piernas y el vientre...» (2000, p. 55).

82.- Para una buena exposición sobre este curioso tratado erótico, véase Heusch (1993, pp. 635-660 y 1999). 
deseo de gozar en los tálamos de Venus. Así pues, la realización de los amores de Calisto y Melibea, más o menos fiel a lo esperado, desvela a cada paso las contradicciones que entraña un protocolo que parece más libresco que real. Los autores lo muestran al desnudo: en el fondo, el varón penado solo desea gozar con la dama, que, en el fondo, desea lo mismo aun con mayor intensidad. Lo revelaron comedias humanísticas como la Poliscena, aunque nunca alcanzaron la gran vitalidad que caracteriza una obra tan compleja y polifónica como la Tragicomedia de Calisto y Melibea.

Los dos amantes siguen, lo hemos visto, el protocolo esperado: el penado Calisto confiesa su pena a Melibea; ella lo rechaza airada, pugnando por disimular su deseo, no sin haberle coqueteado antes; el joven lamenta su desdicha al no poder satisfacer su deseo y se busca una alcahueta con la ayuda de su criado; la alcahueta intenta tentar a la doncella, que sabe las respuestas precisas para guardar las apariencias y concertar todo según su voluntad; Melibea finge pudor ante Calisto, aunque no por mucho tiempo; se resiste y, finalmente, el joven la alcanza del modo más raudo y violento, según era de esperar. Pero sabemos que, pese a la tradición, van quedando al descubierto en el proceso de amores las costuras de este "arte de engaños bien aderezados» ${ }^{83}$ que es el amor. Los códigos, a medida que avanza la obra, van dejando de ser cónsonos con la realidad de un personaje con tanta vitalidad y determinación como Melibea. La joven se queja del convencionalismo rígido que debe seguir, el cual ralentiza el proceso más de lo deseado y exige que este sea dirigido por el varón y no por la mujer. Al final, con todo, la joven afirma que lo ha hecho todo a su voluntad, aunque ciertamente bajo el antifaz que le corresponde a su sufrido "género femíneo».

Cuando los enamorados llegan a la última y mejor meta del amor, las convenciones - sociales o literarias, según se mire- no se corresponden con el deseo íntimo de Melibea. Un mes de encuentros nocturnos le basta para impugnar un arte de amar de siglos, ese que obligaba a la mujer a hacer el amor "en son de forçada, [a]l onbre en son de forçador», ya fuera para salvaguardar la honestidad femenina o ya fuera para excitar al varón que gusta de ese tipo de «modos». Esta preceptiva supone un acto demasiado raudo como para que Melibea pueda vivir plenamente su gozo. Y, además, flagrantemente violento. Con dificultad podría afirmarse, sin el temor de la duda, que "res utrique placuit», pese al júbilo de la joven mientras espera a su amado tras un mes de encuentros nocturnos y pese a su lamento por no haber gozado más de su gozo. Los parlamentos de Melibea ponen en revés como un guante la tradición que ella misma emula junto con su querido al inicio de sus amores. Más allá de la resistencia obligada y de las lágrimas que dulcifican los besos, nunca

83.- La frase es de Ferraresi para referirse al magisterio amoroso de don Amor y doña Venus en el Libro de buen amor (1976, p. 219). 
antes habíamos escuchado una voz femenina europea proponer en pleno factum «mil modos» alternos de hacer el amor y aun ofrecerse a enseñarlos, es decir, a asumir la voz cantante en el acto venéreo. Esos mille modi Veneris, sean cuales sean, representan un rechazo rotundo al socorrido ars amandi medieval, tan finamente poetizado por el goliardo y tan repetido en Europa, y que, además, contaba casi siempre con el beneplácito de los personajes femeninos. Melibea se muestra más afín a las excepciones literarias a estos procederes violentos, como las jubilosas y desenvueltas protagonistas de las jarchas y de la antigua lírica popular hispánica, aunque también es cierto que estos textos no siguen en ningún sentido la preceptiva tradicional que sí siguen fielmente, al menos al principio, Melibea y Calisto. Si hay un ejemplo literario europeo que está muy cerca de la Tragicomedia es la Historia de duobus amantibus de Eneas Silvio Piccolomini, la cual sí se inserta en la misma tradición erotológica y exhibe, además, unos «mil modos» armonizables con los deseos de Melibea, al igual que los «lindos modos» experimentados por Fiometa en Grimalte y Gradisa. La sabiduría erótica de la joven coincide, además, con las descripciones médicas sobre el coito. Es cierto que estos textos también van dirigidos al varón y que muchas veces cumplen una función más médica que erótica, pero revelan un saber erótico que promueve la morosidad en el acto y el placer mutuo de un modo muy cónsono con las propuestas de Melibea y que convive, además, con las fórmulas librescas que la protagonista invalida. Médicos como Juan de Gaddesden y Michael Savonarola, menos fríos que su maestro Avicena, nos suenan por momentos un tanto literarios cuando se sirven de términos propios de la tradición amatoria para describir el ludus venéreo. Para Juan de Gaddesden, es imprescindible el gozo, incluso desde antes del intercurso, lo cual sitúa su discurso más en el ámbito de la delectatio que en el de sterilitate. Ya vimos que el médico incluso prevé la posibilidad de la iniciativa femenina en caso de que ella no termine satisfecha en la pugna erótica. No habría mejor aliado para la joven que las lecciones eróticas recogidas en el Speculum al foder, texto que además exhibe gran parte de la preceptiva tradicional que siguen $\mathrm{Ca}$ listo y Melibea, y el saber de la doncella Teodor, auténtica contrapartida de la Coppina del Specchio d'amore, que defiende unos mille modi Veneris pensados para satisfacer a la mujer sin los prejuicios que suponen lo que manda el decoro. Todos, a fin de cuentas, insisten en evitar las prisas, prolongar - y aun aumentar - el placer, un preludio moroso y delicado lleno de caricias y lindas palabras - como Euríalo y Lucrecia en la obra de Piccolomini-, la consecución del orgasmo mutuo, entre otros detalles. "Amor nichil aliud sit quam delectatio cum gaudio".

Existe, pues, un amplio corpus, aunque no ya literario, que apoya las protestas y propuestas de Melibea, que subrayan la incongruencia entre las fórmulas convencionales, de sobra librescas, y la realidad íntima de las personas de carne y hueso. La acentuada descortesía de Calisto permite 
que el lector simpatice con las propuestas de Melibea, que rechazan el modo tradicional de hacer el amor en la literatura europea. La rebeldía erótica de Melibea, por cierto, es cónsona con la parodia que se proponen los autores desde el inicio de la obra ${ }^{84}$.

Con todo, también hay que admitir que la iniciativa erótica de Melibea no cuenta con ningún antecedente claro que nos permita explicarla enteramente. El saber expuesto en estas páginas, visto desde la distancia temporal, no explica del todo su originalidad, irrepetible en la literatura hispánica, mas nos permite comprender con mayor simpatía sus reacciones y sus pulsiones íntimas. Después de todo, estamos ante aspectos muy humanos, demasiado humanos. Melibea bien podría representar a cualquier muchacha de su tiempo que tuviera su misma fuerza vital, inconforme con las convenciones sociales que limitan su desarrollo pleno, su felicidad.

Por esta y muchas razones, no me queda sino darle la razón a Pedro Cátedra (2001, p. 299) cuando afirma que la Tragicomedia de Calisto y Melibea es «el más genial de los tratados o artes de amores de su tiempo».

\section{Bibliografía}

Adams, J. N. 1982. The Latin Sexual Vocabulary, Duckworth, Londres.

Aguilar Perdomo, María del Rosario 2004. "Las doncellas seductoras y requeridoras de amor en los libros de caballerías españoles», Voz y Letra, 15, 1, pp. 3-24.

Alfonso X 1807. Las siete partidas del rey don Alfonso el Sabio, cotejadas con varios códices antiguos por la Real Academia de la Historia, vol. III, Madrid. Alzieu, Pierre, Robert Jammes e Yvan Lissorgues, (eds.) 2000. Poesía erótica del Siglo de Oro, Crítica, Barcelona.

Amasuno, Marcelino V. 2005. Sobre la ægritudo amoris y otras cuestiones fisiátricas en la Celestina, CSIC, Madrid.

84.- A pesar de lo expuesto en estas páginas, admito que la Tragicomedia de Calisto y Melibea es una de las obras más ambiguas y complejas de la literatura española, pues es capaz de admitir en igualdad las lecturas más contradictorias y aun de crear «escuelas» críticas. Así pues, aunque destaco el lado humano de Melibea, no descarto la hipótesis de Lacarra: «No parece posible que Melibea pueda librarse de la parodia en cuanto que es partícipe en unas escenas de amor subvertidas por la comicidad. ¿Es posible reírnos solamente de Calisto y no de Melibea en medio de sus juegos amorosos?» (1989, p. 24). La estudiosa opina sobre el factum: "El autor no ha querido mostrar una escena tierna, sino jocosa y humillante para Melibea» (2003, p. 54). Es posible que la escena, más allá de reflexionar sobre los modos eróticos, no tenga otra función que la de hacer reír al público. La tónica chistosa del auto queda establecida cuando la dama se recrea con las cancioncillas de Lucrecia, las cuales la equiparan a un lobo viendo ganado y a unos cabritos a punto de mamar ("Saltos de gozo infinitos / da el lobo viendo ganado, / con las tetas los cabritos, / Melibea con su amado»; XIX, pp. 318-319). Precisamente en la pluralidad de interpretaciones, en la posibilidad defender lecturas contradictorias, de decir y desdecirse, es que consiste la riqueza de esta obra maestra. 
Baldwin, John W. 1994. The Languages of Sex: Five Voices from Northern France around 1200, The University of Chicago Press.

Beecher, Donald A., y Massimo Ciavolella 1990. «Jacques Ferrand and the Tradition of Erotic Melancholy in Western Culture», en Jacques Ferrand, A Treatise of Lovesickness, Syracuse University Press, pp. 1-202.

Beltrán, Rafael 1990. "Las "bodas sordas" en Tirant lo Blanc y la Celestina", Revista de Filología Española, 70, 1-2, pp. 91-117.

BlasCo, JAVIER 2015. "En el nombre de Venus: un arte de amar español del siglo XVI", en Lasciva est nobis pagina... Erotismo y literatura española en los Siglos de Oro. Ed. Javier Blasco, Academia del Hispanismo, Vigo, pp. 143-179.

BotTa, Patrizia 1994. "La magia en La Celestina», DICENDA. Cuadernos de Filología Hispánica, 12, pp. 37-67.

Brown, Peter 1993. El cuerpo y la sociedad: los cristianos y la renuncia sexual. Trad. Antonio Juan Desmonts, Muchnik Editores, Barcelona.

Brown, Robert D. 1987. Lucretius on Love and Sex: A Commentary on De rerum natura $I V, 1030-1287$, with Prolegomena, Text, and Translation, Brill, Leiden.

Capellanus, Andreas 1985. De amore. Tratado sobre el amor. Ed. bilingüe de Inés Creixell Vidal-Quadras. El Festín de Esopo, Barcelona.

Carmina Burana 1978. Trad. Lluís Moles y prólogo de Carlos Yarza, Seix Barral, Barcelona.

Carmina Rivipullensia. Cansionero de Ripoll 1986. Ed. bilingüe de José-Luis Moralejo, Bosch, Barcelona.

Castillo, Hernando del 2004. Cancionero general. Ed. J. González Cuenca, Castalia, Madrid, 5 vols.

CÁtedRa, Pedro 1989. Amor y pedagogía en la Edad Media (Estudios de doctrina amorosa y práctica literaria), Universidad de Salamanca.

CÁtedra, Pedro 2001. "Envío», en Tratados de amor en el entorno de Celestina (Siglos XV-XVI). Eds. Pedro Cátedra et al., Sociedad Estatal España Nuevo Milenio, Madrid, pp. 271-320.

CÁtedra, Pedro (ed.) 1986. Tratado de cómo es necesario al hombre amar, en Del Tostado sobre el amor, Stelle dell'Orsa, Barcelona, pp. 7-68.

CÁtedra, Pedro (ed.) 2001. Tratado de cómo al hombre es necesario amar, en Tratados de amor en el entorno de Celestina (Siglos XV-XVI). Eds. Pedro Cátedra et al., Sociedad Estatal España Nuevo Milenio, Madrid, pp. 51-72.

Cherchi, Paolo 1994. Andreas and the Ambiguity of Courtly Love, University of Toronto.

Chrétien de Troyes 1992. Perceval o El cuento del Grial. Trad. Martín de Riquer, Espasa-Calpe, Madrid.

Chrétien de Troyes 2013. El Caballero de la Carreta. Trad. Luis Alberto de Cuenca y Carlos García Gual, Alianza, Madrid.

Ciavolella, Massimo 1976. La malattia d'amore dall'Antichità al Medioevo. Bulzoni, Roma. 
Clef d'amors 1890. Ed. Auguste Doutrepont, Halle.

Corfis, Ivy A. 1996. "Celestina and the Conflict of Ovidian and Courtly Love», Bulletin of Hispanic Studies, 73, pp. 395-417.

Curtius, ERnst Robert 1955. Literatura europea y Edad Media Latina. Trads. Margit Frenk Alatorre y Antonio Alatorre, Fondo de Cultura Económica, México, vol. 2.

Deyermond, Alan D. 1961. "The Text-Book Mishandled: Andreas Capellanus and the Opening Scene of La Celestina», Neophilologus, 43, 3, pp. 218-221.

Deyermond, Alan D. 2008. "El que quiere comer el ave": Melibea como artículo de consumo». Medievalia, 40, pp. 45-52.

Delicado, Francisco 2013. La Lozana andaluza. Eds. Folke Gernert y Jacques Joset, Real Academia Española, Madrid.

Dronke, Peter 1968. Medieval Latin and the Rise of European Love-Lyric, Oxford, 2 vols.

Dronke, Peter 1994. "Andreas Capellanus», The Journal of Medieval Latin, 4, pp. 51-63.

Dronke, Peter 1995. La lírica en la Edad Media. Ariel, Barcelona.

FerRARESI, Alicia C. DE 1976. De amor y poesía en la España medieval: prólogo a Juan Ruiz, El Colegio de México.

Flores, JuAn De 2008. Grimalte y Gradisa. Ed. Carmen Parrilla, Centro de Estudios Cervantinos, Alcalá de Henares.

Frenk, MARgit (ed.) 2003. Nuevo corpus de la antigua lírica popular hispánica (siglos XV a XVII), Castalia, Madrid, 2 vols.

Frenk, Margit 2006. Poesía popular hispánica: 44 estudios, Fondo de Cultura Económica, México.

Frenk, Margit (ed.) 2015. Lírica española de tipo popular, Cátedra, Madrid. Friedman, Lionel J. 1965. "Gradus Amoris», Romance Philology, 19, 2, pp. 167-177.

Gaddesden, JuAn de 1595. Rosa anglica, Augsburgo.

Glaser, EDWARD 1966. "Nuevos datos sobre la crítica de los libros de caballerías en los siglos XVI y XVII», Anuario de Estudios Medievales, 3, pp. 393-410.

GoRdonio, BERnARDO 1991. Lilio de medicina. Edición crítica de la versión española, Sevilla 1495. Eds. John Cull y Brian Dutton, Hispanic Seminary of Medieval Studies, Madison.

Gottifredi, Bartolomeo 1912. Specchio d'amore. Dialogo di messer Bartolomeo Gottifredi nel quale alle giovani s'insegna innamorarsi, en Trattati d'amore del Cinquecento. Ed. Giuseppe Zonta, Laterza, Bari, pp. 249-304.

Gravdal, Kathryn 1991. Ravishing Maidens: Writing Rape in Medieval French Literature and Law, University of Pennsylvania Press.

Green, Otis 1953. "La furia de Melibea», Clavileño, 4, pp. 1-3. 
Haro, MarTa 1993. "Erotismo y arte amatoria en el discurso médico de la Historia de la donzella Teodors, Revista de Literatura Medieval, 5, pp. 113-125.

Herrero Ingelmo, María Cruz, y Enrique Montero Cartelle 2012. "Concepción y erotismo en la literatura médica medieval», Cuadernos de Filología Clásica. Estudios Latinos, 32, 2, pp. 299-314.

Heusch, Carlos 1992. "La Célestine et la tradition amoureuse médiévale». Les Langes Néo-Latines, 279, pp. 5-24.

Heusch, Carlos 1993. La philosophie de l'amour dans l'Espagne du XV' siècle, tesis, Université de la Sorbonne Nouvelle Paris III, <https://tel.archives-ouvertes.fr/tel-00734876/documen $>$. [consultado el 30 de mayo de 2019].

Heusch, Carlos 1999. "De la medicina a l' erotisme. El problema de la prosa científica a l'Speculum al foder (segle Xv)», Rec. Revue d'Études Catalanes, 2, pp. 97-112.

Hissette, Roland 1977. Enquête sur les 219 articles condamnés à Paris le 7 mars 1277, Louvain.

Jacouart, Danielle 2001. «Moses, Galen and Jacques Despars: Religious Orthodoxy as a Path to Unorthodox Medical Views», en Religion and Medicine in the Middle Ages. Eds. Peter Biller y Joseph Ziegler, York Medieval Press, Rochester, pp. 35-45.

Jacouart, Danielle, y Claude Thomasset 1989. Sexualidad y saber médico en la Edad Media. Trad. José Luis Gil Aristu, Labor Universitaria, Barcelona.

Lacarra, María Eugenia 1997. "La ira de Melibea a la luz de la filosofía moral y del discurso médico", en Cinco siglos de "Celestina": aportaciones interpretativas. Coords. José Luis Canet Vallés y Rafael Beltrán Llavador, Universitat de València, pp. 107-120.

LaCARRA, María Eugenia 1989. "La parodia de la ficción sentimental en la "Celestina»», Celestinesca, 13, 1, pp. 11-29.

Lacarra Lanz, Eukene 2000. "El erotismo en la relación de Calisto y Melibea», en El mundo como contienda. Estudios sobre La Celestina. Ed. Pilar Carrasco, Universidad de Málaga, pp. 127-145.

Lacarra Lanz, Eukene 2003. Ars amandi vs. reprobatio amoris. Fernando de Rojas y "La Celestina». Ediciones del Orto, Madrid.

LaCarRa Lanz, EuKene 2007. "¿Ya todos amamos?'. La degradación del amor hereos en Celestina", en Asimetrías genéricas: "Ojos hay que lagañas enamoran». Literatura y género. Ed. E. Lacarra Lanz, Universidad del País Vasco, pp. 33-75.

Lara Cantizani, Manuel 1997. "El equívoco erótico en el otoño medieval español: Tirant lo Blanc y la batalla de amor», en El cortejo de Afrodita: ensayos sobre literatura hispánica y erotismo. Coord. Antonio Cruz Casado, Universidad de Málaga, 137-146.

Lawn, Brian (ed.) 1979. The Prose of Salernitan Questions, Oxford University Press. 
Lida de Malkiel, María Rosa 1962. La originalidad artística de 'La Celestina', EUDEBA, Buenos Aires.

López-BAralt, Luce 1992. Un Kāma Sūtra español, Siruela, Madrid. [Reeditado en Vaso Roto, 2017].

Lorris, Guillaume de, y JeAn de Meun 2003. El Libro de la Rosa. Trads. Carlos Alvar y Julián Muela, Siruela, Madrid.

LOWes, Livingston John 1914. "The Loveres Maladye of Hereos», Modern Philology, 11, 4, pp. 491-546.

Lucena, Luis de 2001. Repetición de amores. Ed. Miguel M. García-Bermejo, en Tratados de amor en el entorno de Celestina (Siglos XV-XVI). Eds. Pedro Cátedra et al., Sociedad Estatal España Nuevo Milenio, Madrid, pp. 93-160.

Madariaga, Salvador de 1972. "Melibea», en Mujeres españolas, EspasaCalpe, Madrid, pp. 51-90. [Publicado originalmente como «Discurso sobre Melibea» en Sur, vol. 10, 1941, pp. 38-69].

Manrique, Gómez 2001. Carta de buena nota con la respuesta de Gómez Manrique, en Tratados de amor en el entorno de Celestina (Siglos XV-XVI). Eds. Pedro Cátedra et al., Sociedad Estatal España Nuevo Milenio, Madrid, pp. 73-80.

Márouez Villanueva, Francisco 1983. "Las lecturas del deán de Cádiz», Cuadernos Hispanoamericanos, 395, pp. 331-345.

Martin McCash, June Hall 2001. "Calisto y la parodia del amante cortés», en Estudios sobre La Celestina. Ed. Santiago López-Ríos, Istmo, Madrid, pp. 475-545.

MarTínez de Toledo, Alfonso 2011. Arcipreste de Talavera o Corbacho. Ed. Michael Gerli, Cátedra, Madrid.

Martínez Torrejón, José M. 1987. "El Libro de buen amor y un manual de cortesía: el Facetus "moribus et vita", Anuario de Letras, 25, pp. 65-90.

MarTínez Torrejón, José M. 2005. "Apártate allá, Lucrecia”. La violación de Melibea", en La Celestina 1499-1999: Selected papers from the International Congress in Commemoration of the Quincentennial Anniversary of La Celestina. Eds. Ottavio di Camillo y John O'Neill, Hispanic Seminar of Medieval Studies, Nueva York, pp. 165-187.

Martorell, Joanot 1974. Tirante el Blanco. Traducción anónima de 1511. Ed. Martín de Riquer, Espasa-Calpe, Madrid, vol. 3.

Martorell, Joanot, y Martí Joan de Galba 2005. Tirant lo Blanc. Trad. J. F. Vidal Jové y prólogo de Mario Vargas Llosa, Alianza, Madrid.

Matos, Kevin 2018a. «De Lucrecia a Melibea: la concepción del erotismo femenino en la Historia de duobus amantibus de Piccolomini y la Tragicomedia de Calisto y Melibea de Rojas», Celestinesca, 42, pp. 189-224.

Matos, KeVIN 2018b. "Siempre muere y nunca acaba de morir el que ama": sobre la muerte del amante en algunos textos del medioevo español», Rivista di Filologia e Letterature Ispaniche, 21, pp. 9-41. 
Miguel Martínez, Emilio de 2000. "Melibea en amores: vida y literatura. "Faltándome Calisto, me falte la vida"», en El mundo como contienda. Estudios sobre "La Celestina», Anejo 31 Analecta Malacitana. Ed. Pilar Carrasco, Universidad de Málaga, pp. 29-66.

The Mirror of Coitus: A Translation and Edition of the Fifteenth-Century Speculum al foderi 1990. Ed. Michael Solomon. The Hispanic Seminary of Medieval Studies, Madison.

Montero-Cartelle, Enriaue 1991. El latín erótico: aspectos léxicos y literarios (hasta el s. I d. C.), Universidad de Sevilla.

Montero Cartelle, Enrioue (ed.) 1983. Constantini Liber de coitu. El tratado de andrología de Constantino el Africano (estudio y edición crítica), Universidad de Santiago de Compostela.

Montero Cartelle, Enrioue (ed.) 1987. Liber minor de coitu. Tratado menor de andrología anónimo salernitano, Universidad de Valladolid.

Morros, Bienvenido 2005. "Oriana y Melibea: de mujer a mujer», Revista de Literatura Medieval, 17, pp. 193-220.

Morros, Bienvenido 2009. "Melancolía y amor hereos en La Celestina», Revista de Poética Medieval, 22, pp. 133-183.

Morros, Bienvenido 2010. "La melancolía de Calisto», Celestinesca, 34, pp. 75-97.

NARDI, BRUno 1959. "L'amore e i medici medievali», en Studi in onore di Angelo Monteverdi. Ed. G. Gerardi Marcuzzo, Società Tip. Editrice Modenese, Módena, pp. 517-542.

Ovidio Nasón, Publio 1914. Heroides and Amores. Ed. bilingüe de Grant Showerman, Loeb, Londres.

Ovidio Nasón, Publio 1957. The Art of Love, and Other Poems. Ed. bilingüe de J. H. Mozley, Loeb, Londres.

Ovidio Nasón, Publio 1995. Amores. Arte de amar. Sobre la cosmética del rostro femenino. Remedios contra el amor. Trad. Vicente Cristóbal López, Gredos, Madrid.

Pagels, Elaine 1988. Adam, Eve, and the Serpent, Penguin, Harmondsworth.

Pamphilus de Amore 1977. Eds. Lisardo Rubio y Tomás González Rolán. Bosch, Barcelona.

PAOLINI, DEVID 2010. «El Libro de buen amory el amor descortés», en Actas del XVI Congreso de la Asociación Internacional de Hispanistas. Coords. Pierre Civil y Françoise Crémoux, vol. 2 (CD-ROM), Iberoamericana, Madrid, p. 46.

Piccolomini, Eneas Silvio 2001. Estoria muy verdadera de dos amantes, Euríalo franco y Lucrecia senesa. Ed. Ines Ravasani, en Tratados de amor en el entorno de Celestina (Siglos XV-XVI). Eds. Pedro Cátedra et al., Sociedad Estatal España Nuevo Milenio, Madrid, pp. 161-217.

Poliscena de Leonardo della Serrata, comedia humanística latina 1996-2000. Ed. bilingüe de Antonio Arbea, Universidad de Chile, Colección de Libros Electrónicos, <http://csociales.uchile.cl/publicaciones/poliscena.pdf $>$. [consultado el 30 de mayo de 2019]. 
Rodríguez de Montalvo, Garci 2012. Amadís de Gaula. Ed. Juan Manuel Cacho Blecua, vol. I, Cátedra, Madrid.

Rodríguez del Padrón, Juan 1982. El triunfo de las donas, en Obras comple-

tas. Ed. C. Hernández Alonso, Editora Nacional, Madrid.

Rojas, Fernando de 2011. La Celestina. Tragicomedia de Calisto y Melibea.

Eds. Francisco J. Lobera et al., Real Academia Española, Madrid.

RojAs, Fernando DE 1993. La Celestina. Comedia o tragicomedia de Calisto y Melibea. Ed. Peter Russell, Castalia, Madrid.

Rubio, Lisardo, y Tomás GonzÁlez Rolán 1977. «Introducción», en Pamphilus de Amore, Bosch, Barcelona, pp. 15-83.

Ruiz, Juan 2015. Libro de buen amor. Ed. Alberto Blecua, Cátedra, Madrid.

Russell, Peter E. 1978. "La magia, tema integral de La Celestina», en Temas de "La Celestina", Ariel, Barcelona, pp. 241-276.

San Pedro, Diego de 2015. Cárcel de amor. Arnalte y Lucenda. Sermón. Ed. José Francisco Ruiz Casanova, Cátedra, Madrid.

Savonarola, Michael 1559. Practica maior, Venecia.

SERnA, FRAY MeLCHOR DE LA 2016. Arte de amor. Primera traducción al castellano del "Ars amandi» de Ovidio. Ed. Javier Blasco, Agilice, Valladolid.

Severin, Dorothy Sherman 1984. "La parodia del amor cortés en "La Celestina"», Edad de Oro, 3, pp. 275-279.

Snow, JosepH T. 2017. "La metamorfosis de Melibea en la Tragicomedia de

Calisto y Melibea», Celestinesca, 41, pp. 153-166.

Speculum al joder. Tratado de recetas y consejos sobre el coito 2000. Trad.Teresa Vicens, José J. De Olañeta, Barcelona.

Taranta, Velasco 1535. Practica medicae que alias Philonium dicitur, Lyon.

Thesaurus linguae Latinae 1900 y ss. Leipzig y Stuttgart, vol. 8, fasc. 8.

Tratado de amores 2001. Ed. C. Gonzalo García, en Tratados de amor en el entorno de Celestina (Siglos XV-XVI). Eds. Pedro Cátedra et al., Sociedad Estatal España Nuevo Milenio, Madrid, pp. 82-92.

Vega, Lope de 2017. Las fortunas de Diana, en Novelas a Marcia Leonarda. Ed. Antonio Carreño, Cátedra, Madrid, pp. 101-175.

Vian Herrero, Ana 1990. «El pensamiento mágico en Celestina, 'instrumento de lid o contienda'", Celestinesca, 14, 2, pp. 41-92.

Vicens, TeResa 2000. "Prólogo", en Speculum al joder. Tratado de recetas y consejos sobre el coito, José J. De Olañeta, Barcelona, pp. 7-11.

Villanova, Arnaldo de 1985. Tractatus de amore heroico, en Opera medica omnia III. Ed. Michael R. McVaugh, Universitat de Barcelona, pp. 9-54. Wack, Mary F. 1990. Lovesickness in the Middle Ages: The Viaticum and its Commentaries, University of Pennsilvania Press.

Whinnom, Keith 1981. La poesía amatoria de la época de los Reyes Católicos, University of Durham. 